Originalveröffentlichung in: Constans, Claire; Vinha, Mathieu da (Hrsgg.): Les grandes galeries européennes: XVIle - XIXe siècles, Paris 201O, S. 353-373 und Abb. 1-24

\title{
HeRRENCHIEMSEE : POURQUOI LOUIS II COPIE la Grande Galerie de Versailles APRÈS LA GUERRE FRANCO-ALLEMANDE
}

\author{
Hendrik Ziegler
}

Si le nom du roi Louis II de Bavière (1845-1886) est entré dans l'histoire, c'est surtout pour ses nombreux et spectaculaires châteaux. La plus célèbre de ces créations est sans doute le Neue Burg Hohenschwangau, connu dans le monde entier sous le nom de Neuschwanstein, situé près de Füssen au bord du lac Forggensee. D'autres ne sont pas moins célèbres, comme le château de Linderhof dans la vallée de Graswangtal, près d'Ettal, ou le Neues Schloss Herrenchiemsee sur l'île Herrenwörth, au milieu du lac Chiemsee. Les premiers plans de ce dernier projet avaient d'abord prévu comme site de construction, en 1868, la vallée de Graswangtal, avant que château et parc ne fussent en grande partie réalisés sur l'île Herrenwörth entre 1873 et 1886.

Depuis qu'ils ont été ouverts au grand public, peu de temps seulement après la mort tragique et mystérieuse du roi dans le lac Starnbergersee le 13 juin 1886, ces palais n'ont cessé d'exercer une grande fascination : leur édification dans des sites retirés de la Haute Bavière, loin de la capitale Munich, leur langage formel éclectique - la fantaisie et la puissante originalité des emprunts aux modèles les plus variés, du Moyen Âge jusqu'aux époques du baroque et du rococo, en passant par des éléments de la création architecturale contemporaine et d'œuvres littéraires et musicales -, indiquent clairement qu'ils n'étaient pas destinés à remplir les fonctions traditionnelles d'habitation et de faste. Ces architectures se présentent plutôt comme des mémoriaux à caractère de monuments historiques dans lesquels Louis II a tenté, sous des formes diverses et 
complexes, de traduire la genèse, le sens et la fonction du pouvoir monarchique de droit divin, tant pour son époque qu'en regard de l'histoire ancienne.

Le nouveau château de Herrenchiemsee, sujet central de cette étude, livre sur ce point les plus précieuses informations. Cette création était naturellement une révérence adressée par le roi de Bavière à son homonyme Louis XIV - souverain absolu par la grâce de Dieu et exemple suprême en son temps. Car en grande partie, le château de Herrenchiemsee et son parc sont une copie du palais et des jardins de Versailles. Nous proposons cependant de montrer ici que le château bavarois va plus loin, qu'il dépasse et sublime son modèle français. Avec cette construction, Louis II ne se contentait pas de rendre hommage à un principe monarchique qui, dans la France des années 1850 et 1860 avec son gouvernement républicain, puis impérial et autocratique, avait depuis longtemps perdu sa crédibilité sociale, mais il s'arrogeait aussi le droit - au titre de descendant de la famille princière encore régnante des Wittelsbach - de démontrer à la dynastie des Bourbons, détrônée de longue date, ses erreurs et ses incohérences, du moins dans la construction de sa plus fameuse résidence royale. Ici se trahit chez Louis II un réflexe de supériorité qui avait jusqu’à présent échappé à la recherche : la conscience, en tant que l'un des derniers représentants vivants de la royauté occidentale, de surpasser, ou du moins d'égaler, le modèle des Bourbons, vénéré mais n'appartenant déjà plus qu’à l'Histoire.

Une attention particulière sera ici portée à la Grande Galerie, baptisée aussi depuis le XIX ${ }^{e}$ siècle galerie des Glaces, l'une des créations architectoniques majeures non seulement du Versailles baroque, mais aussi de sa réplique réalisée près de deux cents ans plus tard. La question se pose de savoir quand est venue à Louis II cette idée d'imiter Versailles, avec la galerie comme pièce maîtresse, et quels intentions et objectifs il poursuivait en reproduisant ce lieu illustre, dans lequel avait été proclamé l'Empire allemand le 18 janvier 1871. On s'interrogera en outre sur les circonstances qui ont permis aux artistes bavarois, dans les années qui ont suivi la guerre franco-allemande, de venir à bout de ces nombreux ouvrages de copies, lorsque se concrétisèrent les plans de reproduction de la galerie des Glaces : une documentation iconographique jusque-là inédite livre pour la première fois des éclaircissements sur le mode de travail des peintres impliqués. 


\section{Le retrait de la vie politique : \\ la césure des années 1865-1866}

Louis II est devenu roi de Bavière à l'âge de 18 ans seulement, après la mort soudaine de son père, Maximilien II, en mars 1864. Dès cette époque, le jeune monarque était intimement convaincu de son titre de monarque par la volonté divine, mais il n'en respecta pas moins la restriction parlementaire de ses droits de souveraineté monarchique imposée par la Constitution de 1818, et il mit en place des gouvernements généralement libéraux qui constituaient pour lui un soutien contre les forces souvent majoritairement conservatrices et ultramontaines de la seconde Chambre du Parlement.

Deux événements des années 1865 et 1866 - l'un relevant de la politique intérieure, l'autre de la politique extérieure - conduisirent cependant Louis II à se retirer très tôt et presque complètement de la vie politique active, et lui firent douloureusement ressentir les divergences entre son pouvoir de décision constitutionnellement restreint et le pleinpouvoir qu'il croyait absolu des monarques prérévolutionnaires ${ }^{1}$. Ces années constituent une césure qui explique pourquoi Louis II engagea aussitôt après - dans les années 1868-1869 - les travaux de construction de ses nombreux châteaux, dans lesquels il voyait la confirmation et la concrétisation architecturale du concept de souveraineté monarchique, qu'il considérait comme dangereusement menacé, sinon déjà anéanti.

Le 10 décembre 1865, Richard Wagner fut contraint de quitter Munich après qu'une large coalition publique lui eut reproché d'avoir détourné Louis II de ses charges de régent et grevé la caisse du Cabinet par ses mises en scène d'opéra dispendieuses. C'est en mai 1864 que Louis II avait fait la connaissance du compositeur, qu'il vénérait déjà au début des années 1860 . Aussitôt après cette rencontre, il l'avait retenu près de lui pour entretenir un échange intellectuel continu. Le roi fut donc profondément affecté de devoir se soumettre à la décision de l'opinion publique, mais aussi des plus hauts cercles du gouvernement, et de laisser repartir en Suisse son exigeant et stimulant ami.

1. Pour une esquisse détaillée de la vie de Louis II de Bavière, voir Heym, 1986. 
À cette déception personnelle s'ajouta, l'été de l'année suivante, un événement de politique extérieure d'une conséquence majeure pour la Bavière, et qui ébranla profondément le sentiment de souveraineté de Louis II : la déclaration de la guerre austro-prussienne née du conflit de longue date entre l'Autriche et la Prusse, relatif à la suprématie à l'intérieur de la confédération germanique. Après avoir essayé d'interférer entre les deux puissances, la Bavière s'était finalement rangée derrière l'Autriche. Les succès militaires rapides de la Prusse contre les alliés autrichiens d'abord, puis l'écrasante défaite des troupes autrichiennes à Sadowa le 3 juillet 1866 entraînèrent la dissolution de la Confédération germanique; la Prusse annexa tous les États ennemis au nord du Main (hormis la Saxe et la Hesse-Darmstadt) et s'assura pour l'avenir le soutien militaire des États du Sud, grâce aux alliances dites offensives et défensive (Schutz-u. Trutzbündnisse). Le 22 août, la délégation bavaroise elle aussi avait dû non seulement entériner le traité de paix convenu, mais aussi le pacte de soutien à la Prusse, s'engageant ainsi par contrat à placer ses troupes sous le commandement du roi de Prusse en cas de guerre défensive. Louis II, qui avait exigé le maintien de son pouvoir de commandement absolu sur ses troupes comme l'un de ses droits de souveraineté incontestables, eut le sentiment d'avoir été trompé par ce pacte et placé sous l'entière dépendance de la Prusse dans les affaires militaires extérieures.

Cette double déception éprouvée et subie dans les années 1865 et 1866 le conduisit à une retraite progressive de la vie publique et politique : le revirement radical de son attitude envers la Prusse et son jugement sur Otto von Bismarck sont aussi symptomatiques de son évolution dans les années suivantes, tant par résignation que par opportunisme. Dans le conflit contre la France, le roi de Bavière se rangea sans réserve aux côtés de la Prusse aussitôt après la déclaration de guerre du 19 juillet 1870 , conformément au pacte d'alliance signé en 1866. Louis II vit alors en Bismarck non seulement un politicien puissant et irréductible, mais aussi le protecteur le plus sûr, celui qui, en secret - et en échange des " contreparties " politiques correspondantes -, lui apportait le soutien financier nécessaire à ses projets d'architecture et de théâtre. En 1870, il se fit payer en argent par Otto von Bismarck son adhésion aux traités dits de Novembre, par lesquels la Bavière ratifiait la fondation de l'Empire allemand sous la conduite de la Prusse, ainsi que la rédaction de la "Lettre à l'empereur ", par laquelle il reconnaissait officiellement 
à Guillaume Ir de Prusse la couronne d'empereur du Reich au nom des princes allemands ${ }^{2}$. Après la saisie des possessions de la maison royale de Hanovre, conduite sous le nom de Welfenfonds (" fonds des Guelfes »), il reçut le 25 septembre 1873 de la Prusse un premier versement annuel d'un montant de 270000 marks. C'est avec cet argent que le roi bavarois acquit l'île Herrenwörth sur le lac Chiemsee, alors mise en vente, et qu'il choisit finalement comme site de la réplique versaillaise planifiée longtemps avant la guerre franco-allemande.

Il convient ici de souligner que, bien avant la guerre de 1870, et plus précisément à la suite des événements de l'année 1866, Louis II s'était adroitement immiscé dans les nouveaux rapports de forces en Allemagne et avait reconnu les revendications d'hégémonie de la Prusse. Il accompagna de ses vœux l'union du Reich de 1871, qu'il encouragea activement sur ordre et paiement de Bismarck, et conservera plus tard sa fidélité à l'Empire. Mais, à l'époque de la proclamation et du couronnement du premier empereur allemand Guillaume ${ }^{\text {er }}$ dans la galerie des Glaces de Versailles, le 18 janvier 1871, Louis II avait depuis longtemps intimement renoncé à toute haute ambition politique pour se dévouer plus amplement à la réalisation de ses divers projets artistiques. La référence au château de Versailles retenue pour son nouveau château de Herrenchiemsee ne répondait donc nullement à un besoin de s'approprier la résidence du roi français par le biais d'une copie dans un geste triomphal de vainqueur.

\section{La copie de Versailles dans la vallée de Graswangtal}

Bien avant le début de la guerre franco-allemande, Louis II avait eu l'idée de copier en dimensions réduites les pièces du château de Versailles qui retenaient spécialement son attention : la galerie et la chambre de Louis XIV. Les premières ébauches concernant ce projet architectural - germe du futur château de Herrenchiemsee - avaient vu le jour dès 1868. À cette époque, elles se rapportaient encore au site de Graswangtal, localité toute proche de Linderhof, où les travaux de l'un de ses autres châteaux avaient été entrepris peu de temps auparavant. Ce n'est qu'en 1878 - cinq ans 
après l'acquisition de l'île Herrenwörth sur le lac Chiemsee - que le projet de copie de Versailles, qui s'était entre-temps considérablement agrandi, put être engagé. Parce qu'elles livrent des informations fondamentales sur l'intention du roi quant à sa reproduction du château français, nous proposons de récapituler ici brièvement les étapes de la conception du site de Graswangtal pour les années 1868 à 1873.

Dès les années 1850, Maximilien II, le père de Louis II, avait acquis et fait transformer pour ses chasses une ferme située dans cette vallée enserrée dans les montagnes de Haute Bavière, proche du couvent d'Ettal, fondé au milieu du XIV siècle par l'empereur Louis le Bavarois. En 1869, Louis II avait entrepris des travaux de modernisation dans cette " maisonnette royale ", devenue en 1876 un imposant petit château rococo paré d'une magnifique façade, le château de Linderhof. Mais, parallèlement aux transformations progressives de cette demeure paternelle, il caressait depuis la fin de 1868 le plan d'une imitation de Versailles. Jusqu'à 1873, il commanda à l'architecte Georg von Dollmann, directeur du Bureau royal de la construction, l'élaboration de douze projets toujours agrandis, sans pouvoir se résoudre à l'un ou à l'autre : les premiers plans de 1868 ne prévoyaient qu'un pavillon tout en longueur abritant les copies des pièces majeures, c'est-à-dire la galerie des Glaces réduite à sept fenêtres, deux salons mitoyens et, à l'arrière, sur l'axe médian, la chambre à coucher de Louis XIV. Mais dès 1869, le pavillon fut agrandi d'un bâtiment à triple corps, pour atteindre finalement au tournant de l'année 1869-1870, dans le septième projet, des dimensions presque égales au modèle versaillais avec une galerie comptant treize fenêtres! Le modeste projet initial était devenu au bout de cinq années seulement un ensemble d'une telle envergure qu'il fallut finalement, en 1873 , chercher un lieu plus adéquat que l'étroite vallée montagneuse : il fut trouvé sur l'île Herrenwörth ${ }^{3}$.

Toute la planification fut conduite sous le nom de code "Tmeicos Ettal ", une anagramme - composé du mot fantaisiste "Tmeicos " et d'Ettal, le nom du monastère voisin - de la formule "L'État c'est moi " (expression apocryphe, comme nous le savons aujourd'hui, attribuée au jeune Louis XIV ${ }^{4}$ ).

3. Rauch, $1993:$ 53-56; Baumgartner, $1981:$ 132-137.

4. Bluche, $1990: 1065$ sq. 


\section{Le nouveau site : I'île Herrenwörth sur le lac Chiemsee}

Engagée à partir de 1873, la conception du nouveau château de Herrenchiemsee allait encore exiger cinq années avant la pose de la première pierre, le 21 mai 1878, avec l'intention de développer le projet "Tmeicos Ettal " élargi. La mise en route du chantier fut sans doute stimulée par le troisième séjour à Paris de Louis II, du 21 au 28 août 1874, au cours duquel il put visiter pour la première fois le château et le parc de Versailles le 25 août, jour même de son vingt-neuvième anniversaire ${ }^{5}$. Sa connaissance de Versailles n'était jusque-là nourrie que par une lecture intensive de toutes les publications qu'il lui avait été possible de se fournir sur le château des Bourbons et sa royale lignée d'habitants ${ }^{6}$. Lors d'un premier voyage à Paris en 1857 - voyage qui, contre toute attente, n'a pas été pris en considération par les chercheurs allemands -, Louis, alors prince héritier, n'avait visité que le musée des Souverains aménagé au Louvre par l'empereur Napoléon III $^{7}$. Lors d'un deuxième séjour à Paris, du 20 au 29 juillet 1867, il n'avait pu effectuer la visite prévue à Versailles, contraint à un retour anticipé à Munich après la mort de son oncle, le roi Otto I ${ }^{\text {er }}$ de Grèce ${ }^{8}$. Une autre visite à Versailles, envisagée pour l'automne 1869, avait également dû être annulée?. C'est seulement lors de son troisième voyage, en 1874, qu'il put enfin accomplir cette visite, si ardemment désirée. En l'honneur du roi, la République française fit actionner les jeux d'eau du jardin, sans susciter la moindre action de protestation chez la population française, comme l'avaient craint les cercles diplomatiques allemands. Lors de ce séjour, le roi put revoir le palais du Louvre

5. Pour une étude détaillée des voyages à l'étranger de Louis II, voir Böhm, 1924:363-389 et pour le voyage de 1874 spécialement : 375-384.

6. La délégation bavaroise à Paris dut fréquemment satisfaire aux commandes de livres du roi, voir Evers, 1970: 242 et Nöhbauer, 1995: 70.

7. Viel-Castel, $1883: 80$; Granger, $2005: 333$.

8. Louis II voyagea à Paris sous le pseudonyme "Comte von Berg ", notamment pour pouvoir visiter l'Exposition universelle. Des excursions le conduisirent entre autres à Compiègne et au château médiéval de Pierrefonds, reconstruit depuis 1848 par Eugène-Emmanuel Violletle-Duc, voir Böhm, 1924 : 363-375.

9. À ce propos, voir : Paris, archives du ministère des Affaires étrangères, Affaires diverses politiques 1815-1896, Bavière 11, Lettre du marquis de Cadore, ministre Plénipotentiaire de Bavière à Son Excellence le Prince de la Tour d'Auvergne, ministre des Affaires étrangères français, Munich, le 22 octobre 1869. 
et visiter pour la première fois le tombeau de Napoléon $I^{\text {er }}$ dans le dôme des Invalides, ainsi que le château de Fontainebleau ${ }^{10}$. Compte tenu de son intérêt passionné et constant pour Versailles, on peut considérer que Louis II a été, depuis la fin des années 1860, et notamment après ce troisième séjour à Paris en 1874, l'un des plus grands connaisseurs de l'ancienne résidence des rois de France. On ne saurait par conséquent être surpris que le treizième projet - le premier directement conçu pour Herrenwörth -, élaboré en 1874-1875 par Georg von Dollmann, égale parfaitement en dimensions le château de Versailles : conformément à son modèle baroque, la Grande Galerie comptait dès lors dix-sept fenêtres ${ }^{11}$.

Reporté sur une feuille du cadastre de l'île, ce treizième plan constitua la référence de base pour toutes les étapes de construction ultérieures. Dans les années qui suivirent, il s'est essentiellement agi de définir l'emplacement du château sur l'île, sa rigoureuse orientation est-ouest et la configuration du parc qui devait entourer l'édifice. Les décisions furent arrêtées en 1876 , après deux autres étapes de réflexion ${ }^{12}$. Après la pose de la première pierre, en mai 1878 , la structure du bâtiment à triple corps autour de la cour de Marbre put être achevée en $1881^{13}$. L'aménagement intérieur se poursuivit encore activement jusqu'à la fin de 1885 , date à laquelle il dut être interrompu en raison de l'insolvabilité des caisses du Cabinet royal des finances. À la mort du roi n'était achevé que ce triple corps central du bâtiment, les deux ailes ajoutées à angle droit à l'édifice central n'étant qu'au stade des soubassements, ou du gros œuvre. La partie sud fut rasée en 1886, celle du nord détruite en 1907.

Les pièces les plus significatives du corps principal du château restaient la Grande Galerie, orientée vers l'ouest sur le jardin, avec ses deux salons mitoyens, ainsi que la chambre à coucher de Louis XIV située dans l'axe

10. Böhm, $1924: 375-384$. À notre grande surprise, il n'existe, ni aux archives du ministère des Affaires étrangères ni aux Archives nationales de Paris, de documentation pertinente sur ce voyage particulièrement intéressant à Versailles en 1874. Les archives versaillaises ne fournissent aucun document ni aucune photographie de la visite de Louis II au château en 1874. Les journaux intimes de Louis II à partir de l'année 1869 ayant disparu dans un incendie lors de la Seconde Guerre mondiale, nous ignorons l'impression que fit sur lui le château; le dernier voyage en France de Louis II, du 24 au 27 août 1875, le conduisit à Reims, ville du couronnement des rois de France, voir Böhm, $1924: 384-389$.

11. Rauch, 1993 : ill. 18.

12. Ibid. : 60-64, 69-73; Nöhbauer, 1995 : 70-72.

13. Rauch, 1993 : ill. 46; Baumgartner, 1981 : 141, ill. 250. 
médian vers la cour de Marbre. Au-delà, n’avaient été presque entièrement terminés à la mort de Louis II que les appartements intérieurs répartis autour de la cour de Marbre, avec surtout - dans une réplique extrêmement singulière - l'escalier des Ambassadeurs, entièrement détruit dès 1752 au château de Versailles, et la chambre à coucher privée de Louis XV.

Contre toute attente, Louis II ne se rendit pas une seule fois sur l'île de Herrenwörth avant 1881, bien qu'une grande partie du château ait déjà été achevée à cette date. C'est seulement à partir de 1882 qu'il s'y rendit chaque année en septembre ou au début d'octobre, logeant alors généralement dans des pièces spécialement aménagées à son intention dans l'édifice dit Ancien Château, couvent de chanoines sécularisé depuis 1803, situé à la pointe nord de l'île. Il ne passa qu'une seule nuit au nouveau château lors de son dernier séjour, en septembre 1885, dans l'enfilade des pièces de l'aile nord, réplique des appartements de Louis XV au château de Versailles ${ }^{14}$.

\section{Les peintures dans la galerie des Glaces du nouveau château de Herrenchiemsee}

La question se pose de savoir comment des artistes bavarois ont réussi, dans la période de grande tension entre la France et l'Allemagne que sont les années 1870 et 1880 , à se faire une idée de Versailles et à le reproduire pour satisfaire les attentes de Louis II. Il ne sera ici question que des imitations de la Grande Galerie et des deux salons adjacents - le salon de la Guerre et le salon de la Paix -, ces pièces appartenant à la suite de salles du nouveau château de Herrenchiemsee dans lesquelles apparaît le plus clairement l'ambition, si respectueuse fût-elle, qui présida à la réalisation de ce château, de surpasser avec des moyens artistiques la dynastie des Bourbons. Au château de Versailles, les plafonds peints de la Grande Galerie et des deux salons adjacents avaient été réalisés entre 1680 et 1686

14. Petzet, Neumeister, $1995: 141$; Nöhbauer, $1995: 70$ sq. 
par Charles Le Brun et son atelier ${ }^{15}$. Des documents jusque-là inédits, provenant du fonds de compensation (Ausgleichsfonds) des Wittelsbach, livrent aujourd'hui pour la première fois des indices plus précis concernant l'ensemble du château bavarois, la manière dont les artistes allemands impliqués ont procédé pour ce travail d'imitation, et quels moyens techniques ont été mis en œuvre.

La réalisation de la galerie des Glaces du nouveau château de Herrenchiemsee sous la direction de Dollmann dura de 1878 à 1881 . Les travaux de peinture commencèrent le $1^{\text {er }}$ avril $1880^{16}$. Les éléments majeurs étaient achevés en 1881, même si la réflexion sur la peinture du plafond - en particulier sur ses coloris - se poursuivit jusqu'en 1885 (HT. 21). Les peintures sont l'œuvre de Ferdinand Piloty, Wilhelm Hauschild, Eduard Schwoiser (H.-T. 22), Angelo comte de Courten, Joseph Watter et Franz Widnmann ${ }^{17}$. Les riches ouvrages de stuc ont été réalisés par Philipp Perron et son atelier.

Contrairement à l'idée jusqu'ici admise dans la littérature sur le sujet, il semble qu'il n'y ait jamais eu, en vue des travaux de peinture, de "voyage de groupe" des artistes bavarois pour l'étude de la galerie des Glaces à Versailles ${ }^{18}$. Les artistes auront plutôt été envoyés à plusieurs reprises, individuellement ou par deux, à Versailles, ce qui sur le plan politique paraît stratégiquement plus ingénieux et plus raffiné qu'une action concertée. Plusieurs de ces séjours à Versailles sont documentés : ainsi, vers octobre 1873 , le ministre des Travaux publics a-t-il satisfait à la demande de l'ambassadeur bavarois à Paris en accordant au photographe de la cour de Louis II, Joseph Albert, l'autorisation de photographier quelques salles du château de Versailles ${ }^{19}$. En juin 1875, Jobst Riegel

15. Sur la Grande Galerie après sa dernière restauration en 2004-2007, voir La galerie des Glaces..., 2007.

16. Rauch, $1993: 108-111$.

17. Ibid. : 300, annexe des sources : Q 132-133 (schéma avec l'attribution des œuvres aux différents artistes).

18. Sur I'hypothèse d'un voyage à Versailles en 1879 de tout un groupe des peintres bavarois aux fins de copies, voir Petzet, 1968: 62 et Petzet, Neumeister, 1995: 134.

19. Paris, Archives du ministère des Affaires étrangères, Affaires diverses politiques 18151896, Bavière 11, Lettre du ministre des Travaux publics, Direction des Bâtiments civils, Palais de Versailles, à M. Rudhart, Versailles, le 21 octobre 1873. Un plan de Versailles calqué à I'encre rouge dans l'ouvrage de Jacques-François Blondel (1752-1756), avec des annotations 
se rendit à Versailles pour y réaliser toute une série d'aquarelles du château et des jardins, parmi lesquelles une planche reproduisant la galerie des Glaces $^{20}$. À la fin de l'été de la même année, Georg von Dollmann et Eduard Schwoiser se rendirent à Versailles, pour y étudier ensemble le bâtiment et le décor peint ${ }^{21}$. Angelo, comte de Courten, séjourna à son tour à Versailles en novembre 1879 pour y étudier non seulement la galerie, mais aussi les deux salons adjacents, le salon de la Guerre et le salon de laPaix. En 1885, c'est Edmund Laire qui est détaché à Versailles - comme en témoignent la lettre et la documentation iconographique plus précisément abordées ci-après - apparemment pour y effectuer les derniers contrôles.

Le roi disposait d'un modèle de scène de théâtre qui reproduisait en format réduit la galerie des Glaces de Versailles et qui lui permettait la transposition en trois dimensions de ses idées du lieu : Christian Jank, qui avait conçu ce décor de scène en 1873 pour la représentation de la pièce Das Alter eines großen Königs (La vieillesse d'un grand roi) de Lockroy et Arnould, en avait ensuite réalisé une maquette pour le roi, enthousiaste $^{22}$. Par ailleurs, Louis II pouvait se représenter les salles versaillaises (en trois dimensions) grâce à des photographies, pour la plupart prises par son photographe de cour Joseph Albert ${ }^{23}$.

Les peintres qui s'étaient vu confier l'imitation de la galerie versaillaise travaillaient aussi principalement à partir de photographies des reproductions graphiques des peintures de plafond de la Grande Galerie. On pense par exemple à la reproduction intégrale de la Grande Galerie de Versailles réalisée en cinquante-deux planches gravées par Jean-Baptiste Massé en $1752^{24}$. Les prises de vue photographiques en noir et blanc des eaux-fortes historiques étaient ensuite colorées sur place, à Versailles même, par les artistes, et complétées le cas échéant des commentaires

indiquant au photographe les salles à photographier pourrait dater de l'un de ces voyages d'Albert; voir Petzet, $1968: 210$, cat. $\mathrm{n}^{\circ} 750$ et Evers, $1970:$ ill. 98.

20. Baumgartner, 1981 : 160, ill. 279.

21. Petzet, Neumeister, $1995: 134$, n. 231.

22. Ibid. : ill. 190; Hommel, $1963: 167$ sq.

23. Seules quelques rares prises de vue historiques de Versailles ont été conservées au König Ludwig II.-Museum; voir par exemple la vue de la chambre à coucher de Louis XIV, prise vers 1875, dans Baumgartner, 1981 : 137, ill. 239.

24. La Grande Galerie..., 1752. Voir à ce propos la récente parution de Jean-Gérald Castex (2007). 
correspondants. Une lettre adressée le 7 novembre 1879 de Versailles par le peintre Angelo, comte de Courten, à son beau-frère, l'architecte du nouveau château de Herrenchiemsee, Georg von Dollmann, nous livre à ce sujet des informations très intéressantes. Alexander Rauch a publié pour la première fois cette source en 1993 :

Versailles 7 Nov 1879 : Cher Georges, Ci-joint tu trouveras les photogr. peintes ainsi qu'un dessin très primitif de l'emplacement des peintures du Salon de la Guerre. Je pense que tu connaîtras facilement la place de chaque lunette par les quelques figures indiquées. En faisant un petit travail je me suis un peu occupé de la manière dont tout cela est fait. J'en ai parlé assez longuement à Meu. [Monsieur] Le Cte. Cl[é]ment de Ric [Ris] (Conservateur du Musée) et il m’a dit que tous les grands tableaux de la Galerie des Glaces avaient été peints sur toile et appliqués ensuite au plafond. Suivant ses indications j'ai examiné attentivement et à l'aide d'une bonne lorgnette les dites peintures et j'ai pu facilement me convaincre de ce que le Conservateur affirmait. Les peintures des plus grands tableaux sont coupées en deux parties et au centre de la voûte on voit clairement la trace de ce travail.

Les peintures des tableaux plus petits sont seulement coupées [à] l'endroit o[ù] commence la courbe. Sur les bords de la toile de chaque tableau on distingue parfaitement les petits clous qui assujet[t]issent la toile au mur pour plus de solidité.

Les lunettes des Salons de la Paix et de la Guerre sont excentré[e]s de la même façon mais les coupoles sont peintes à l'huile sur le mur même.

On comprend facilement qu'il aurait été difficile d'adapter la toile à la courbe de la voûte. La manière d'appliquer ces toiles au mur est celle connue sous le nom de "marouflage " qui consiste à mettre derrière la toile une forte couche de blanc pour faire adhérer la peinture au mur.

Le coté pratique de tout cela serait de pouvoir tous travailler dans la même salle sans trop d[']échafaudages.

Les quelques retouches nécessaires seraient assez faciles à faire ensuite sur place. J'ai voulu te redire tout cela non pas pour te donner un conseil, tu n'en as pas besoin, mais pour te faire connaître ce que je tiens de bonne source. Mon travail de peinture est fini, mais comme j'ai quelques commissions à faire pour Sa Majesté, je ne pourrai partir d'ici avant la fin du mois. Irène me charge de te dire mille belles embrasses ainsi qu’à Eugénie. Croi[s]-moi en attendant / Ton d[é]voué beau-frère Angelo

5, Avenue de St. Cloud ${ }^{25}$

25. Rauch, 1993 : 108 sq et annexe des sources : 303 sq, Q 144. La lettre est rédigée en français. Pour une meilleure lisibilité, j'ai apporté quelques corrections orthographiques à la transcription de Rauch; elles sont indiquées entre crochets. 
Angelo von Courten avait manifestement joint à sa lettre des photographies colorées des compartiments des peintures des plafonds de Versailles. La lettre témoigne de la tentative des artistes d'analyser au mieux la technique picturale et le montage des peintures du plafond dans les années 1870. Le courrier de Courten fait clairement apparaître que les responsables français sur place, ici Clément de Ris, ont accueilli avec bienveillance les demandes des artistes bavarois et se sont montrés ouverts et serviables à leur égard ${ }^{26}$.

La technique de travail brièvement évoquée dans la lettre de Courten est illustrée dans une planche d'Edmund Laire lors du voyage d'études à Versailles en 1885. Il s'agit d'une photographie collée sur carton d'après une gravure de Nicolas Gabriel Dupuis le Jeune, datant du XVIII ${ }^{\mathrm{e}}$ siècle, qui porte le titre "Renouvellement d'Alliance avec les Suisses, 1663" et qui reproduit le compartiment ovale correspondant du plafond de Versailles (H.-T. 20). Laire a coloré la photo et indiqué en marge sur le carton les données exactes des coloris des différentes parties marquées sur la photo. Dans le premier commentaire en haut à gauche, rédigé en français, sont par exemple mentionnées les parties en ton doré, et celles en imitation marbre: "Toutes les parties toujours en jaune indiquent les parties dorées. Le reste est de marbre [...]»

Un autre dessin de détail réalisé lors de ce voyage montre une fois encore que la peinture originale de la galerie n'a été étudiée le plus souvent qu'à la lumière artificielle et à l'aide de reproductions graphiques (Ill. 1). La planche montre - sous l'inscription manuscrite révélatrice rédigée en français "Description de la partie indiquée sur la gravure " - l'un des quatre médaillons entourés de la sentence ludovicienne NEC PLURIBUS $I M P A R^{27}$ qui figurent en leur centre la tête-soleil couronnée d'Apollon et qui occupent une place privilégiée dans le plafond de la galerie versaillaise, le long de l'axe médian de la voûte en berceau ${ }^{28}$.

26. Les conservateurs responsables cette décennie-là du château, Eudore Soulié, Louis Clément de Ris et Charles Gosselin (respectivement en service de 1852 à 1876, de 1876 à 1882 et de 1882 à 1892) ne manifestaient apparemment aucune espèce d'aversion envers les visiteurs allemands; les choses allaient changer avec la nomination à la direction de Pierre de Nolhac, qui était entré dans le service du musée de Versailles en 1887 et avait été nommé conservateur en 1892 : Nolhac, $2002: 164$ sq, 171 sq.

27. "Car il égale les autres [princes] ", traduction de l'auteur.

28. Reproduction de ce détail du plafond de Versailles dans Milovanovic, $2007: 131$. 


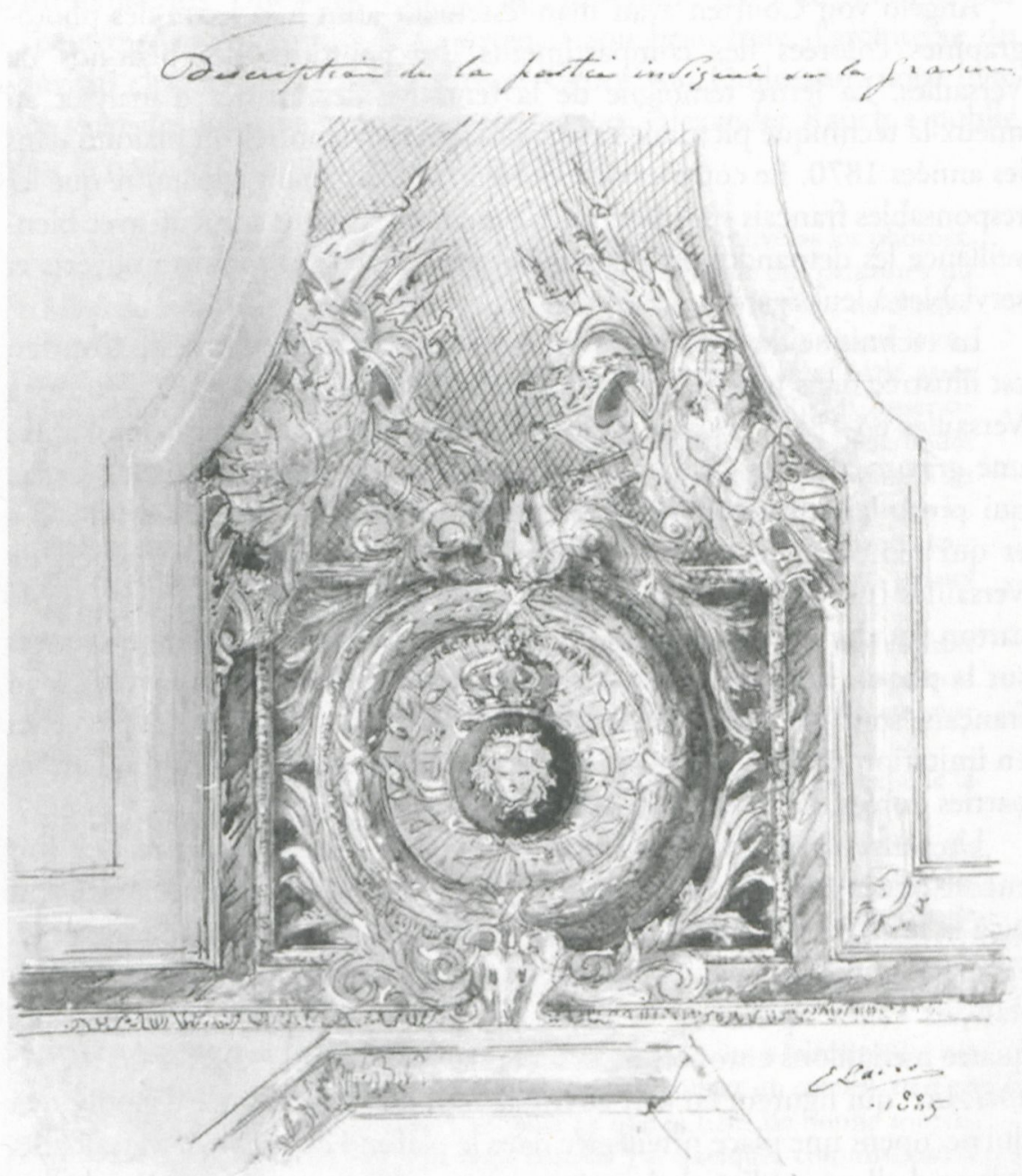

III. 1, Edmund Laire, esquisse d'un détail du château de Versailles, titrée :

" Description de la partie indiquée sur la gravure ", 1885.

Un autre type de dessin figure dans une planche rectangulaire de dimension moyenne une vue d'ensemble du plafond envisagé pour le nouveau château de Herrenchiemsee. Cette planche couverte d'une grille quadrillée, et vraisemblablement réalisée en 1880, représente un résumé 
des efforts préalables à la division précise du plafond ${ }^{29}$. La grille permettait un transfert aisé sur des formats plus grands, puis vraisemblablement l'extrapolation de pochoirs à la dimension requise dont les artistes se servaient pour la réalisation.

Il est vraisemblable qu'aucun des artistes ayant pris part à la peinture de la galerie de Herrenchiemsee n'a eu à réaliser de sa main des dessins ou copies dans la galerie de Versailles, mais que tous ont pu choisir parmi les reproductions graphiques mises à leur disposition la documentation de base nécessaire à leur travail. La reproduction photographique de ces documents était un moyen astucieux qui garantissait un point de départ fiable et peu coûteux pour une étude directe sur place. L'artiste n'ayant plus le souci du dessin de l'œuvre, il pouvait en revanche se concentrer entièrement sur la conception générale des coloris et en reproduire au fur et à mesure le résultat sur la photo rapportée.

La réalisation des peintures de la galerie du château de Chiemsee, fidèles à l'original dans le choix des coloris, mais dans l'ensemble beaucoup plus claires par la volonté du roi, a été, pour ainsi dire, un défi technique accueilli par les artistes avec pragmatisme et esprit d'innovation. Mais l'aspect technique de la construction de la galerie n'était pas ce qui intéressait Louis II.

\section{Une surenchère de Versailles}

Il est indiscutable que l'objectif du roi bavarois avec son château de Herrenwörth était une reproduction aussi fidèle que possible de Versailles, mais sous la forme qui aurait dû être celle du château selon lui, et sur la base de ses études historiques. Plusieurs divergences fondamentales entre l'imitation et le modèle confortent cette thèse.

Les façades extérieures donnant sur la cour de Marbre ne sont pas parementées de briques et pierres de taille ouvragées comme c'est le cas pour le modèle historique, mais seulement de pierres de taille, ou plus

29. Anonyme, Einteilung der Decke der Spiegelgalerie im Neuen Schloß Herrenchiemsee, 1880?, dessin à l'encre, environ 23 x $75 \mathrm{~cm}$, Munich, Wittelsbacher Ausgleichsfonds, B VIII 109. 
exactement, pour des raisons de coût, d'une imitation consistant en un crépi jaunâtre sur briquetage. Dollmann conçut l'élévation du mur en se référant aux façades de la cour des Princes de Versailles, située au sud de la cour de Marbre : à partir de là, il reprit l'élévation du mur à trois étages coiffé d'un toit plat à l'italienne en remplacement de l'articulation des façades à deux étages surmontées des toits français en bâtière du corps de bâtiment central versaillais datant des années $1630^{30}$.

Dollmann et son maître d'ouvrage Louis II revenaient ainsi sur une critique déjà maintes fois formulée sous Louis XIV, et qui avait déjà trouvé sa plus pertinente formulation dans l'Architecture Françoise de JacquesFrançois Blonde,l datée du milieu de XVIII ${ }^{\mathrm{e}}$ siècle, à savoir l'absence d'unité entre les façades donnant sur la cour d'honneur et celles donnant sur le jardin ${ }^{31}$. Dans son Grand Projet élaboré entre 1771 et 1774 , l'architecte du roi lui-même, Ange Jacques Gabriel, avait déjà proposé une harmonisation radicale des deux façades du château, mais seul le remaniement d'une première aile de la résidence, adjacente à la Cour royale, avait été accompli jusqu'en 1774, avant l'interruption complète du chantier pour des raisons de coût ${ }^{32}$.

Par cette conception innovatrice de la façade de la cour de Marbre dans le nouveau château de Herrenchiemsee, Louis II et son architecte Dollmann renouaient avec cette critique et purent se vanter d'avoir réussi à Herrenchiemse l'harmonisation des façades orientale et occidentale qui n'avait jamais été réalisée dans le bâtiment français original.

Des " améliorations " et "corrections " furent ainsi entreprises non seulement à l'extérieur, mais aussi à l'intérieur du château, notamment dans la Grande Galerie. Il ne s'agissait pas seulement pour Louis II de la reproduire et de la montrer telle qu'elle avait dû être, selon lui, sous Louis XIV. Il avait aussi l'ambition d'améliorer l'effet esthétique et la lisibilité d'une partie du plafond en ordonnant la création de nombreux éléments plastiques qui n'étaient que peints dans le modèle français. Charles Le Brun et son atelier avaient seulement cerné de moulures en stuc doré les grandes peintures et les petits tableaux historiques polygonaux

30. Rauch, 1993: 78 sq.

31. Blondel, 1752-1756, vol. $4: 130$.

32. Baulez, 2004. 
le long de l'axe médian du plafond de la voûte en berceau; tous les autres encadrements, les architectures en trompe-l'œil, les draperies, les amours, cariatides et atlantes, les figures mythologiques, allégoriques et autres représentations scéniques avaient été directement peints à l'huile sur le plafond crépi. Dans la galerie de Herrenchiemsee, toutes ces parties furent reproduites en trois dimensions par le sculpteur Philipp Perron et réalisées en stuc par les ouvriers de son atelier. La dorure uniforme et mate de ces parties remplace, à Herrenchiemsee, la palette de couleurs de Le Brun. Le rythme des compartiments du plafond peint dans la galerie bavaroise est cependant indéniablement plus lisible et offre une meilleure transition optique des éléments de l'articulation architectonique des murs et du plafond.

C'est à la galerie d'Apollon du palais du Louvre, dont le décor commencé en 1661 n'avait été achevé que vers la moitié du XIX ${ }^{\mathrm{e}}$ siècle $^{33}$ (H.-T. 16), que Louis II a manifestement emprunté l'idée de cette conception plastique générale plus puissante de tous les éléments du plafond qui entourent les champs picturaux. Il avait pu visiter cette galerie lors de ses séjours à Paris en 1857 , et surtout en $1874^{34}$. Une note d'instruction du 23 juillet 1878, envoyée à la demande du roi par le secrétaire de la cour, Ludwig von Bürkel, à Georg von Dollmann probablement, indique que la galerie d'Apollon devait servir de modèle pour le " rajustement " (Aufrüstung) plastique de la galerie des Glaces du nouveau château de Herrenchiemsee :

La décoration du plafond dans la galerie des Glaces doit être la même que la décoration plastique de la salle Apollon du Louvre composée de télamons [atlantes] supportant les nervures. Entre eux, sur la corniche principale, se dressent des groupes d'amours dotés des attributs des signes du zodiaque $^{35}[\ldots]$

\section{Bresc-Bautier, 2004.}

34. Voir notes 7 et 10.

35. "Die Gewölbe-Dekoration im Spiegelsaal soll wie die plastische Dekoration des Apollo-Saales im Louvre ausgeführt werden, welche aus Telamonen [=Karyatiden] besteht, die die Gurttheilungen tragen. Zwischen diesen stehen auf dem Hauptgesimse Amorettengruppen, welche mit den Attributen des Thierkreises versehen sind [...]", Baumgartner, 1981:260, n. 33 . 
Mais ces éléments plastiques du décor de la galerie des Glaces du nouveau château de Herrenchiemsee ne sont pas la seule différence avec Versailles. Les deux galeries different aussi par leurs dimensions : $75 \mathrm{~m}$ de long et $10,5 \mathrm{~m}$ de large, sous une hauteur de $12,5 \mathrm{~m}$ pour la galerie bavaroise; $73 \mathrm{~m}$ de long seulement, $10,5 \mathrm{~m}$ de large, $12,5 \mathrm{~m}$ de haut pour la galerie versaillaise ${ }^{36}$. Ces différences, au fond minimes mais néanmoins sensibles, qui donnent plus de volume aux salles, ne sont pas le seul fait de la galerie des Glaces au château de Herrenchiemsee. Le tableau comparatif des dimensions des plus importantes salles de Versailles et de leurs pendants à Herrenchiemsee, dressé par Georg von Dollmann le 17 août 1880 , révèle que les dimensions des pièces ont été délibérément et systématiquement augmentées dans le château bavarois par rapport au modèle français ${ }^{37}$.

La raison de cette stratégie de surenchère spatiale méthodique peut s'expliquer par des considérations pratiques de l'architecte: Dollmann voulait sans doute conserver à l'imitation une dimension assez grande, pour pouvoir satisfaire les fréquents désirs de changements dans la distribution des pièces de son maître d'œuvre. Comme dans un jeu de construction, un système modulaire variable devait permettre les modifications à l'intérieur de l'enveloppe généreusement dimensionnée du bâtiment. Ce besoin de Louis II de vouloir " améliorer " le modèle versaillais, tant sur le plan qualitatif que sur le plan des dimensions, semble néanmoins trahir aussi un sentiment de supériorité par rapport à la famille des Bourbons.

Les dispositions de Louis II à l'égard de Louis XIV et des Bourbons étaient à l'évidence ambivalentes et pas seulement empreintes d'admiration. Pour lui, Louis XIV était en effet l'un des plus éminents représentants de l'une des anciennes maisons royales d'Europe, face auquel il faisait figure de parvenu, la Bavière n'ayant accédé au titre de royaume que par décret de Napoléon I ${ }^{\text {er }}$ en 1806. Mais les Bourbons avaient été

36. Evers, $1970: 269$. L'idée de Rauch (1993: 108) selon laquelle la galerie de Chiemsee serait de $20 \mathrm{~m}$ plus longue que son modèle français est erronée.

37. Georg von Dollmann, Dimensionen der einzelnen Räume in den Schlössern Herrenchiemsee $u$. Versailles, Munich, 17 août 1880, papier, planche double, $32 \times 21 \mathrm{~cm}$, Munich, Bayerisches Hauptstaatsarchiv, Geheimes Hausarchiv, Kabinettsakten Ludwig II. 341, ill. dans France-Bayern, 2006: 412, $\mathrm{n}^{\circ}$ 168. Sous le tableau portant le $\mathrm{n}^{\circ} 12$ sont indiquées, pour la galerie de Chiemsee, les dimensions 257,0 sur 36,0 pieds, pour celle de Versailles 240,0 sur 32,0 pieds. 
chassés du trône français une première fois en 1792, puis définitivement en 1830; la lignée auxiliaire des Bourbons, la maison d'Orléans, avait elle-même été destituée en 1848. Les Wittelsbach au contraire, qui régnaient depuis la seconde moitié du XII ${ }^{\mathrm{e}}$ siècle en Bavière, étaient encore au pouvoir. Fort de cet état de fait historique, Louis II semble avoir considéré comme légitime d'aborder Versailles non seulement avec une admiration muette, mais aussi avec une volonté délibérée de faire mieux et un impératif besoin de surpasser le modèle. C'est à lui, un Wittelsbach, que revenait la mission historique de perpétuer le principe monarchiste, de l'honorer et de lui rendre sa splendeur.

Cette attitude subtile et nuancée de Louis II, qui ne relevait pas d'une francophilie aveugle, n'a pas été prise en considération par ses critiques. Après la mort du monarque, l'intérêt qu'il avait porté aux palais des Bourbons suscita plutôt l'étonnement du large public admis à découvrir ses châteaux, et quelquefois même, fût-ce modérément, la protestation. C'est sans doute l'historien de l'art bourgeois-libéral et antisocialiste Wilhelm Lübke qui fut le plus virulent. Dans un essai rédigé l'année même de la mort du roi bavarois, il exprima sa stupéfaction de découvrir qu'à l'époque de la fondation du Reich un prince allemand ait eu l'idée d'imiter l'art de cour des rois français, et spécialement de Louis XIV, qui avait dévasté le Palatinat ${ }^{38}$. Il déclara en outre les copies des châteaux de la monarchie française réalisées par le roi bavarois complètement inintéressantes sur le plan artistique, et socialement superflues ${ }^{39}$.

Luise von Kobell, mieux disposée à l'égard du roi, fit preuve de plus de mesure. Dans l'étude qu'elle publia en 1900, König Ludwig II. von Bayern und die Kunst, elle donne d'emblée au lecteur de son parcours virtuel à travers le château ce conseil discret : "Il faut ici faire complètement abstraction du patriotisme allemand, et aborder les choses et les admirer d'un point de vue purement esthétique ${ }^{40}$ ".

Mais Louis II était peut-être plus patriote qu'il n'est généralement admis. Son nouveau château de Herrenchiemsee ne devait pas seulement

38. Lübke, $1886: 525$.

39. Ibid. : $531 \mathrm{sq}$.

40. "Man muß dabei von deutschem Patriotismus völlig abstrahieren und rein vom ästhetischen Standpunkte aus betrachten und bewundern », Kobell, 1906: 123. 
être une modeste et admirative reproduction de Versailles, mais une surenchère visuelle créée à partir de la connaissance de sa propre responsabilité historique et dynastique de l'édifice qui avait été, comme aucun autre, un espace de la vie et de l'activité monarchiques.

\section{Bibliographie}

Albrecht, Dieter, 2000, "König Ludwig II. von Bayern und Bismarck », Historische Zeitschrift, n 270/1 : 39-64.

Baulez, Christian, 2004 [1982], "Le Grand Projet ", in M. Gallet et Y. Bottineau (dir.), Les Gabriel, Paris, Picard : 182-193.

Baumgartner, Georg, 1981, Königliche Träume: Ludwig II. und seine Bauten, Munich, Hugendubel.

BlONDEL, Jacques François, 1752-1756, Architecture Françoise, ou Recueil des plans, élévations, coupes et profils des Eglises, Maisons Royales, Palais, Hôtels \& Edifices les plus considérables de Paris [...], Paris, C.-A. Jombert, 4 vols. BluCHE, François (dir.), 1990, Dictionnaire du Grand Siècle, Paris, Fayard. BöHM, Gottfried von, 1924, Ludwig II. König von Bayern: sein Leben und seine Zeit, Berlin, Engelmann.

BRESC-BAutier, Geneviève (dir.), 2004, La galerie d'Apollon au palais du Louvre, Paris, Gallimard-Musée du Louvre.

CASTEX, Jean-Gérald, 2007, "Du tableau à la gravure ou le dessin d'interprétation au XVIII ${ }^{\mathrm{e}}$ siècle: cinquante-deux dessins pour une œuvre?", La revue des musées de France/Revue du Louvre, $\mathrm{n}^{\circ} 3: 96-104$.

Evers, Hans Gerhard, 1970 [1939], Tod, Macht und Raum als Bereiche der Architektur, Munich, Fink.

France-Bayern: Bayern und Frankreich: Wege und Begegnungen, 1000 Jahre bayerisch-französische Beziehungen, France-Bavière: allers et retours, 1000 ans de relations franco-bavaroises, 2006, cat. expo. (Bayerisches Hauptstaatsarchiv, Munich, 21 février au 17 avril 2006 - Hôtel de Soubise, Paris, 10 mai au 7 août 2006), Paris-Munich, Biro-Centre historique des Archives nationales-Staatliche Archive BayernsWaakirchen-Oreos.

La galerie des Glaces: histoire \& restauration, 2007, Dijon, Éditions Faton. 
La Grande Galerie de Versailles et les deux Salons qui l'accompagnent peints par Charles Le Brun, Premier Peintre de Louis XIV, dessinés par JeanBaptiste Massé [...], 1752, Paris, Imprimerie royale.

Granger, Catherine, 2005, Lempereur \& les arts: la liste civile de Napoléon III, Paris, École des chartes.

Heym, Sabine, 1986, « König Ludwig II. - Leben, Politik, Bauten. Ein chronologischer Überblick », in G. Hojer(dir.), KönigLudwig II.-Museum Herrenchiemsee: Katalog, Munich, Hirmer : 127-147.

Hommel, Kurt, 1963, Die Separatvorstellungen vor König Ludwig II. von Bayern: Schauspiel, Oper, Ballett, Munich, Laokoon-Verl.

KobelL, Luise von, 1906 [1898], König Ludwig II. von Bayern und die Kunst, Munich, Verlag der Vereinigten Kunstanstalten.

König Ludwig II. und die Kunst, 1968, cat. expo. (aile de la salle des Fêtes, résidence de Munich, 20 juin au 15 octobre 1968), Munich, Prestel.

LÜBKE, Wilhem, 1886, "König Ludwig II. und die Kunst ", in Kunstwerke und Künstler: Sammlung vermischter Aufsätze, Breslau, Schottlaender : 523-539.

Milovanovic, Nicolas, 2007, "Le système iconographique : un édifice symbolique ", in La galerie des Glaces : histoire \& restauration, Dijon, Éditions Faton : 120-133.

NÖHbauer, Hans F., 1995 [1985], Auf den Spuren König Ludwigs II: ein Führer zu Schlössern und Museen, Lebens- und Erinnerungsstätten des Märchenkönigs, Munich, Prestel.

NolHaC, Pierre de, 2002, La résurrection de Versailles: souvenirs d'un conservateur 1887-1920, édition présentée et annotée par C. Pincemaille, Paris-Versailles, Perrin-Société des amis de Versailles.

Petzet, Michael, 1968, "König Ludwig II. und die Kunst ", in König Ludwig II. und die Kunst, cat. expo. (aile de la salle des Fêtes, résidence de Munich, 20 juin au 15 octobre 1968), Munich, Prestel : 7-70.

Petzet, Michael; NeumeIster, Werner, 1995, Ludwig II. und seine Schlösser: die Welt des Bayerischen Märchenkönigs, Munich-New York, Prestel.

RauCH, Alexander, 1993, Schloß Herrenchiemsee: Räume und Symbole, Munich-Berlin, Köhler und Amelang.

Viel-Castel, Horace de, 1883, Mémoires du comte Horace de Viel Castel sur le règne de Napoléon III (1851-1864), t. IV : 1857-1858, Paris, chez tous les libraires. 



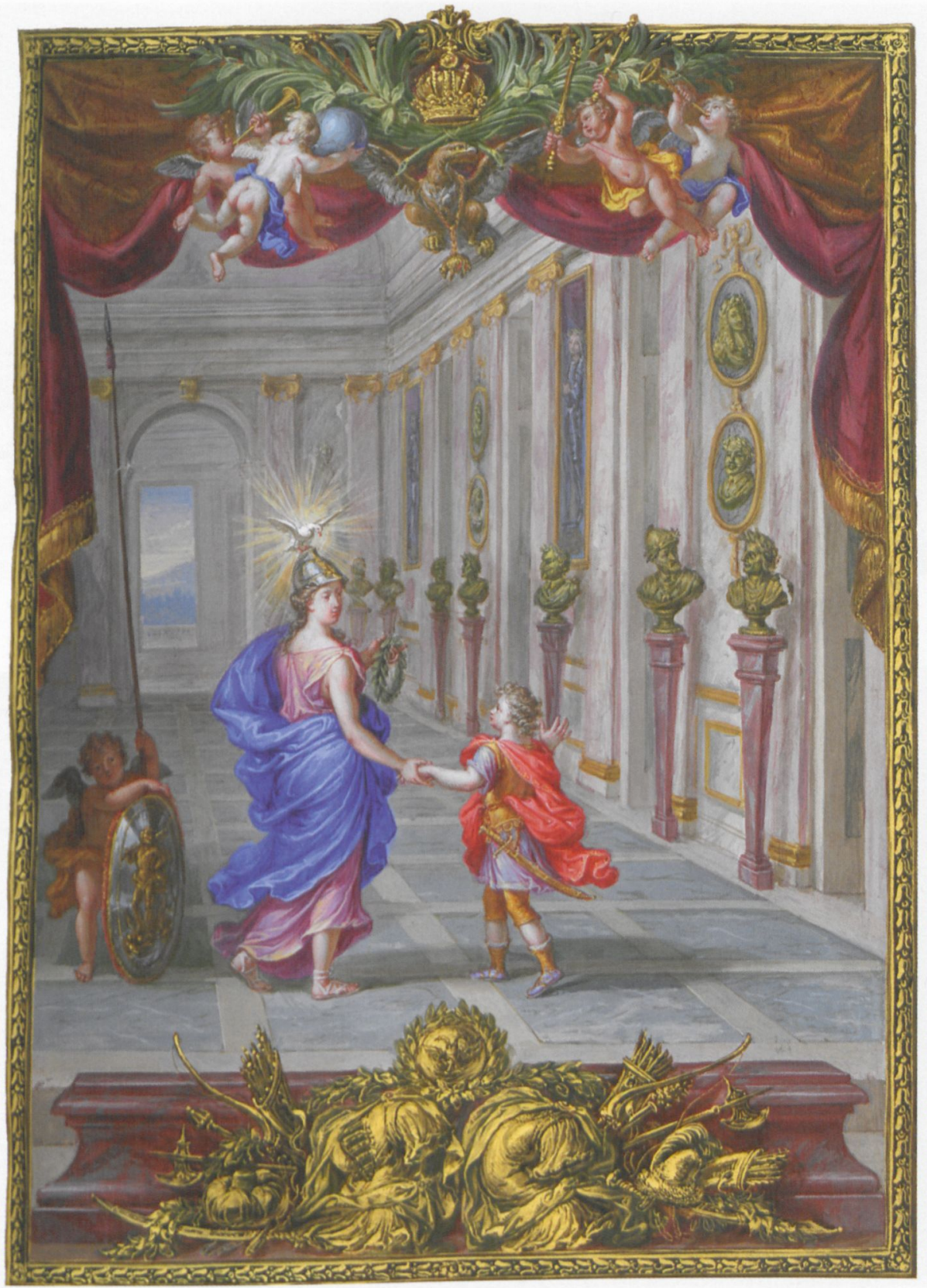

1. L'archiduc Charles d'Autriche guidé par Minerve dans une galerie virtuelle de portraits des Habsbourg, in Andreas Paur, Theatrum Austriacum, 1696, Chicago, Newberry Library. 


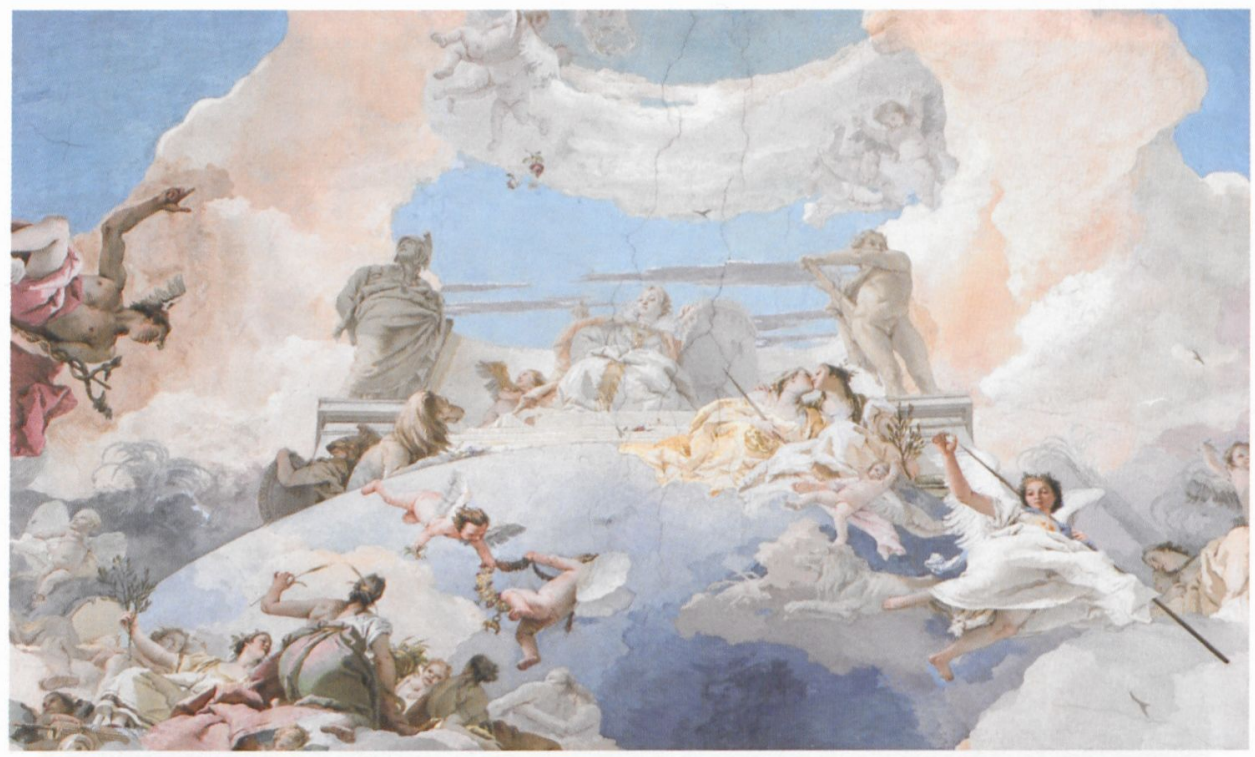

2. Giovanni Battista Tiepolo, la Monarchie entre Minerve et Apollon (détail de la fresque), 1764, Madrid, Palais royal, salle du Trône.

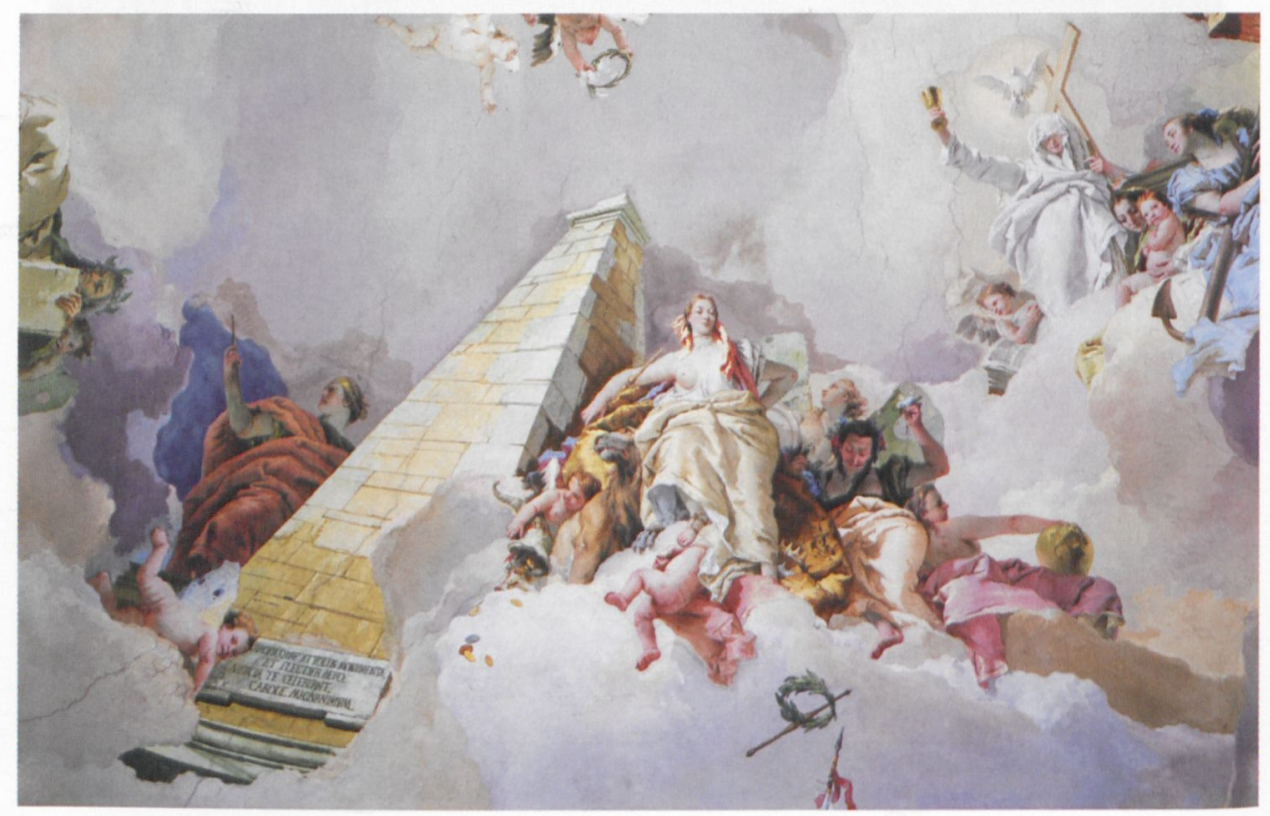

3. Giovanni Battista Tiepolo, monument à la gloire de Charles III (détail de la fresque), 1764, Madrid, Palais royal, salle du Trône. 


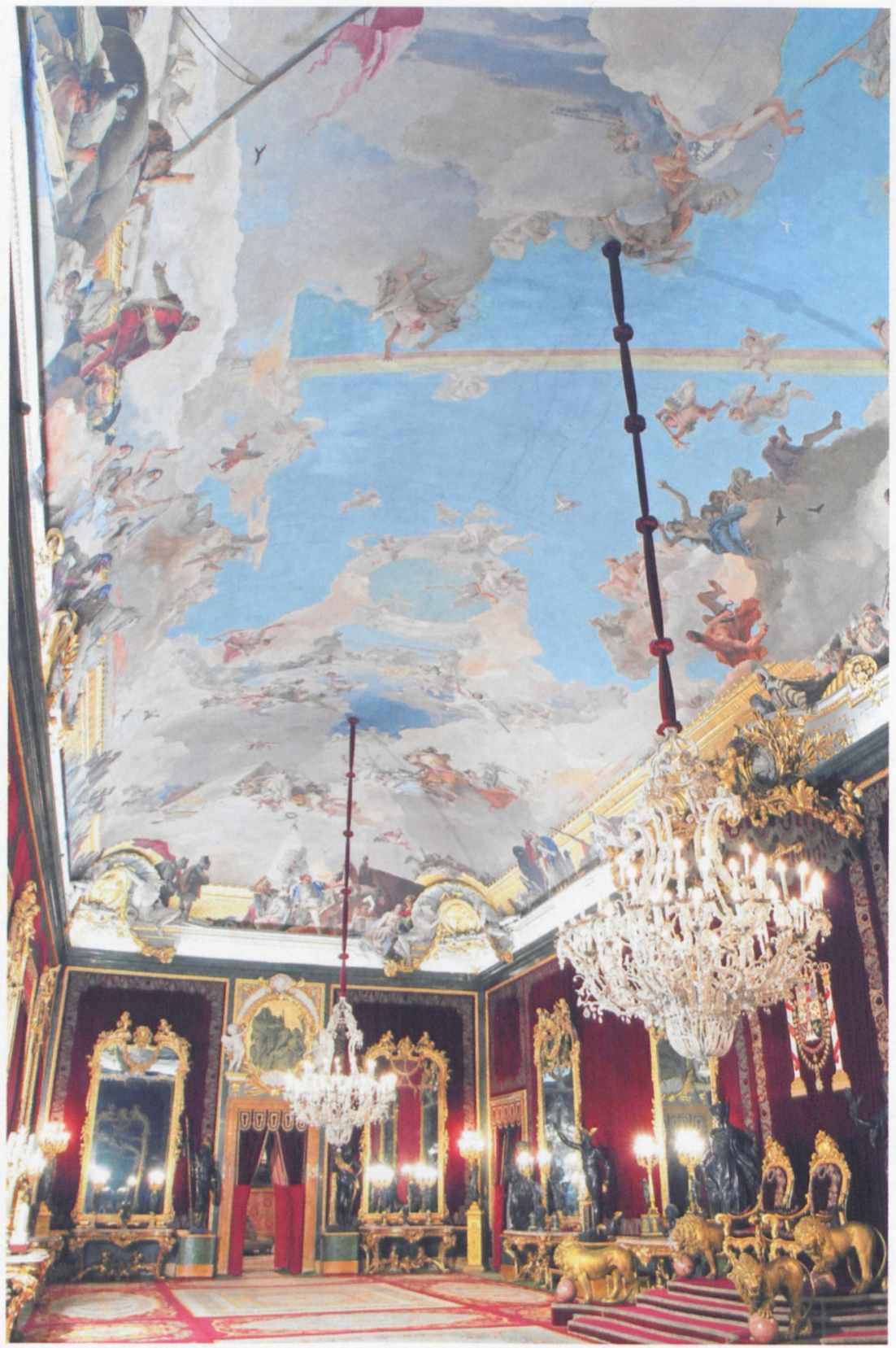

4. Vue générale montrant l'extrémité occidentale de la salle du Trône, Madrid, Palais royal. 


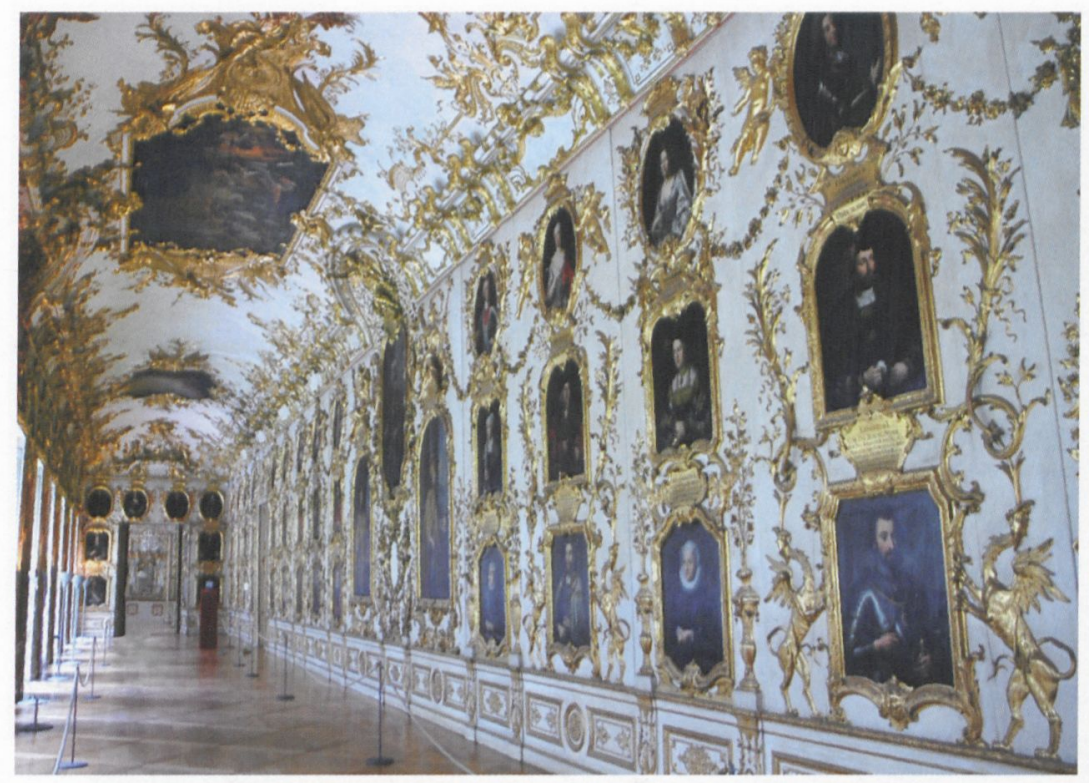

5. La galerie des Ancêtres de la Résidence de Munich.

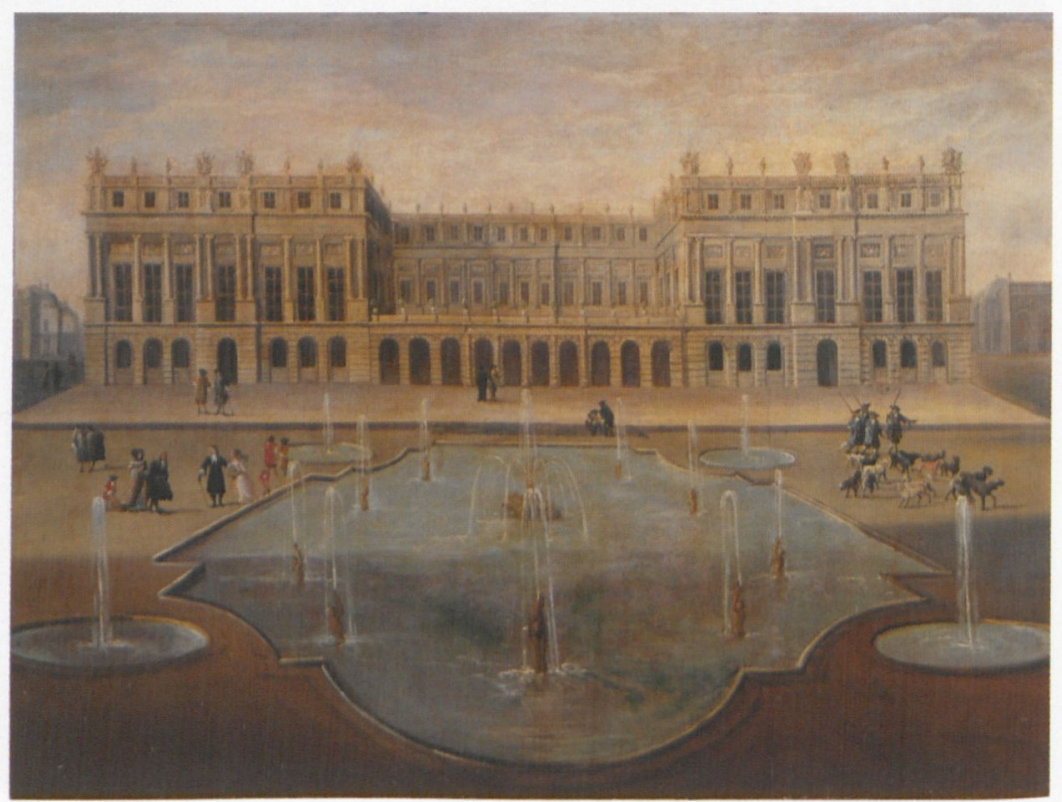

6. Anonyme, Vue du château de Versailles, sur le parterre d'eau, vers 1675 , Versailles, musée national des châteaux de Versailles et de Trianon. 




7. Vue générale vers l'est de la galerie du palais Colonna à Rome. 


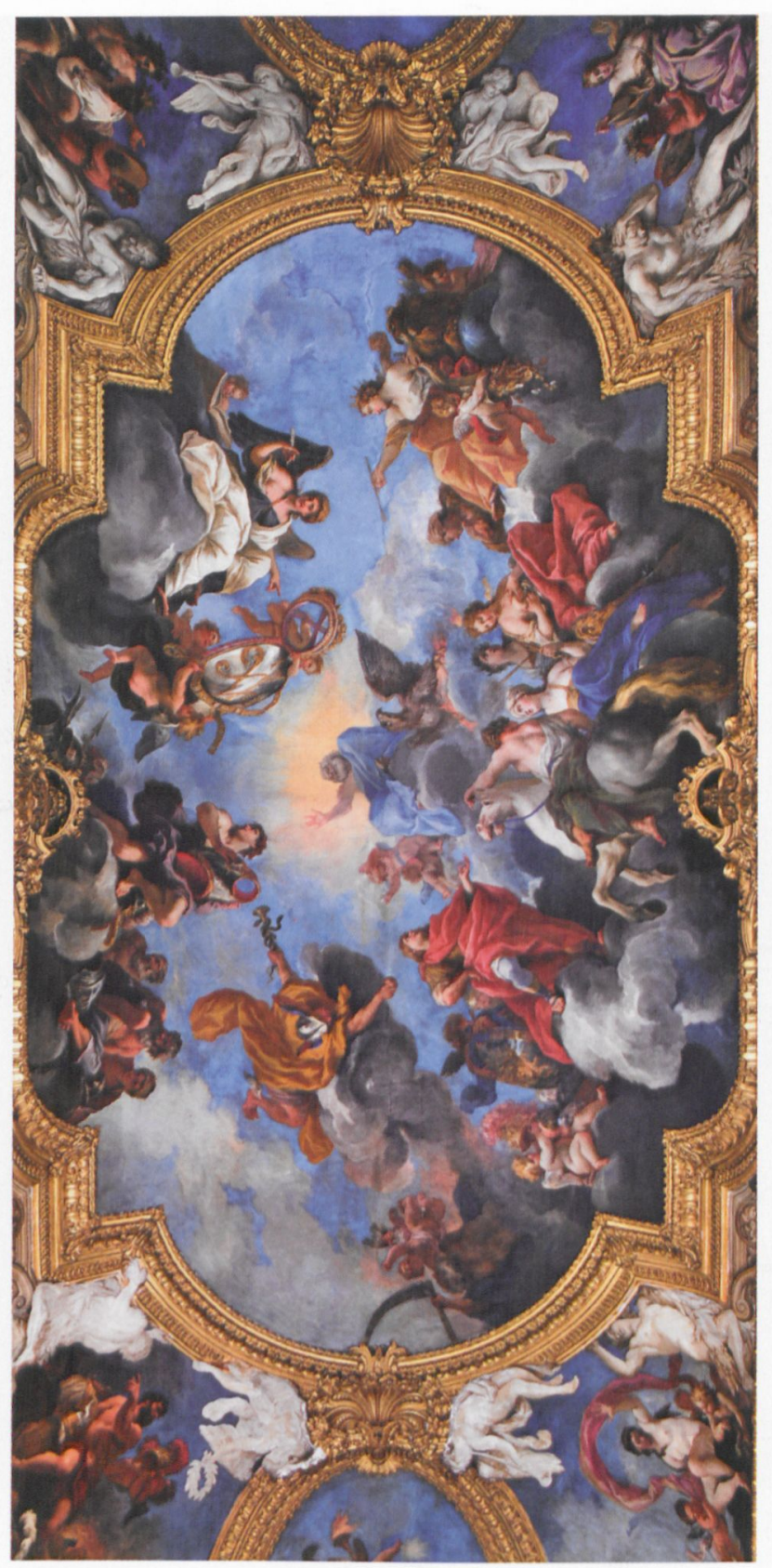

8. Détail de la voûte de la Galleria del Daniel, vers 1690-1693, Turin, Palais royal. 


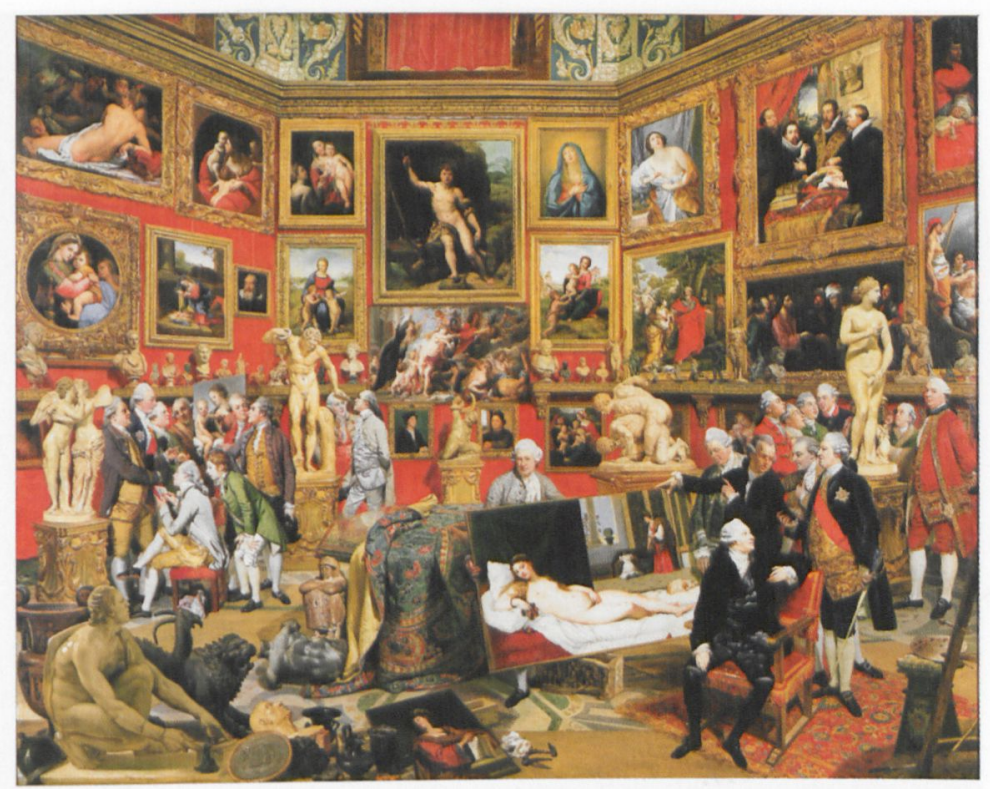

9. Johann Joseph Zoffany, La Tribune des Offices, 1772-1777, château de Windsor.

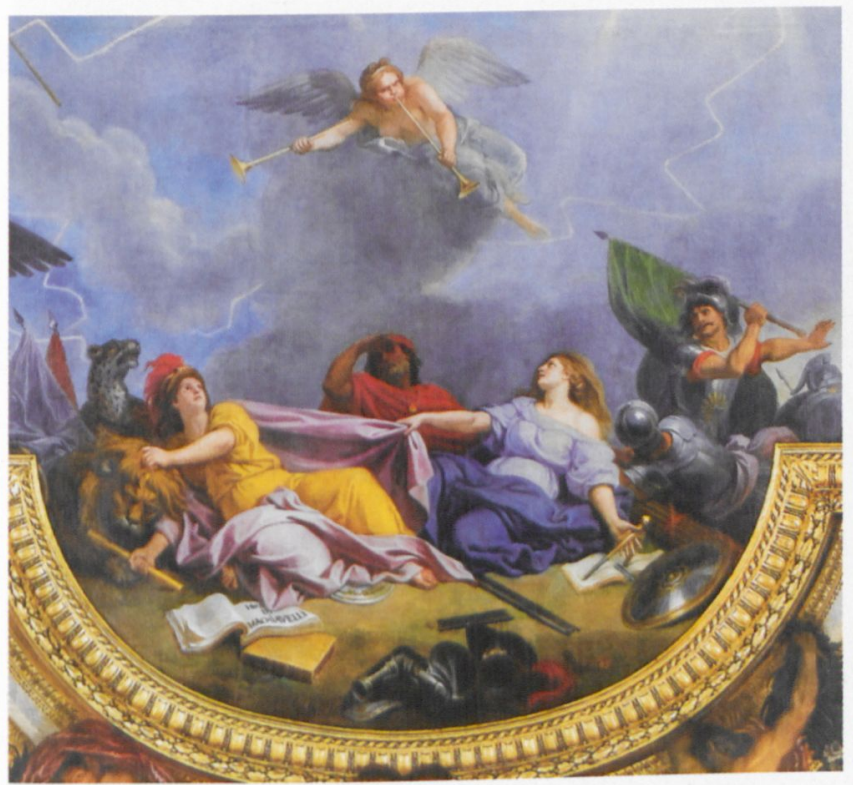

10. Charles Le Brun, Mesures des Espagnols rompues par

la prise de Gand, 1679-1682, château de Versailles, galerie des Glaces, après restauration (2006). 


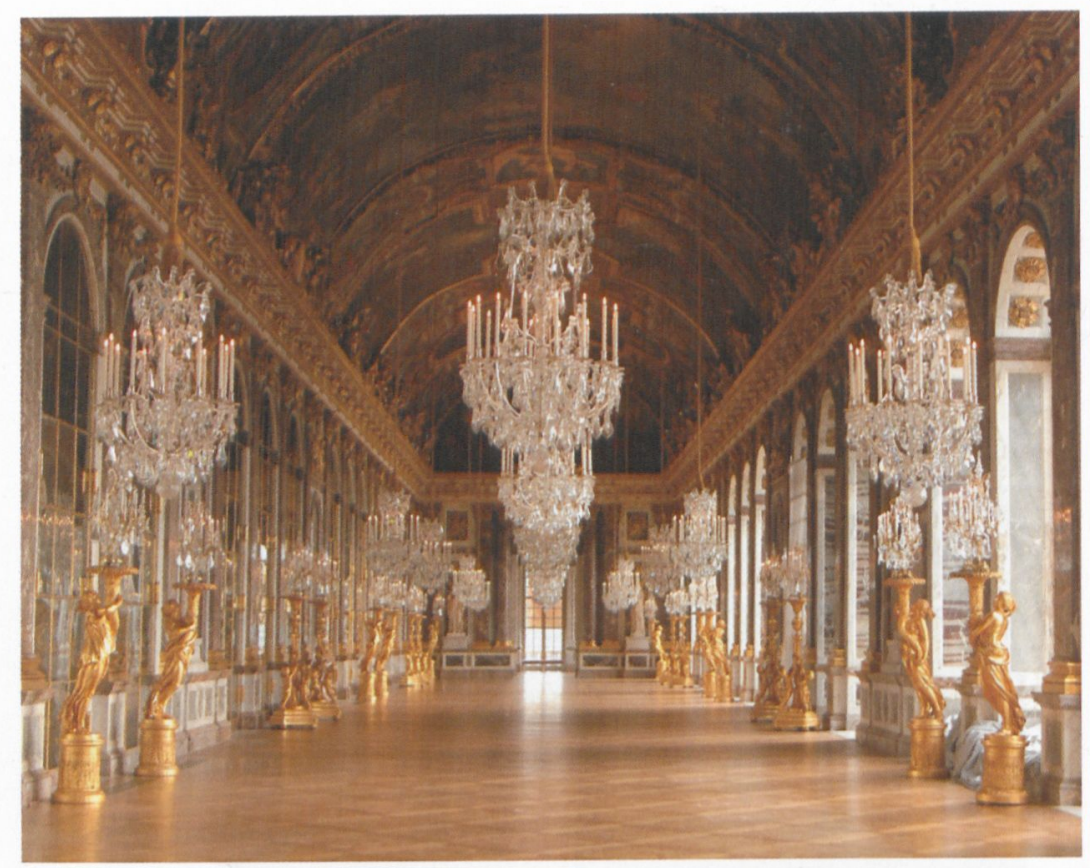

11. La galerie des Glaces du château de Versailles.

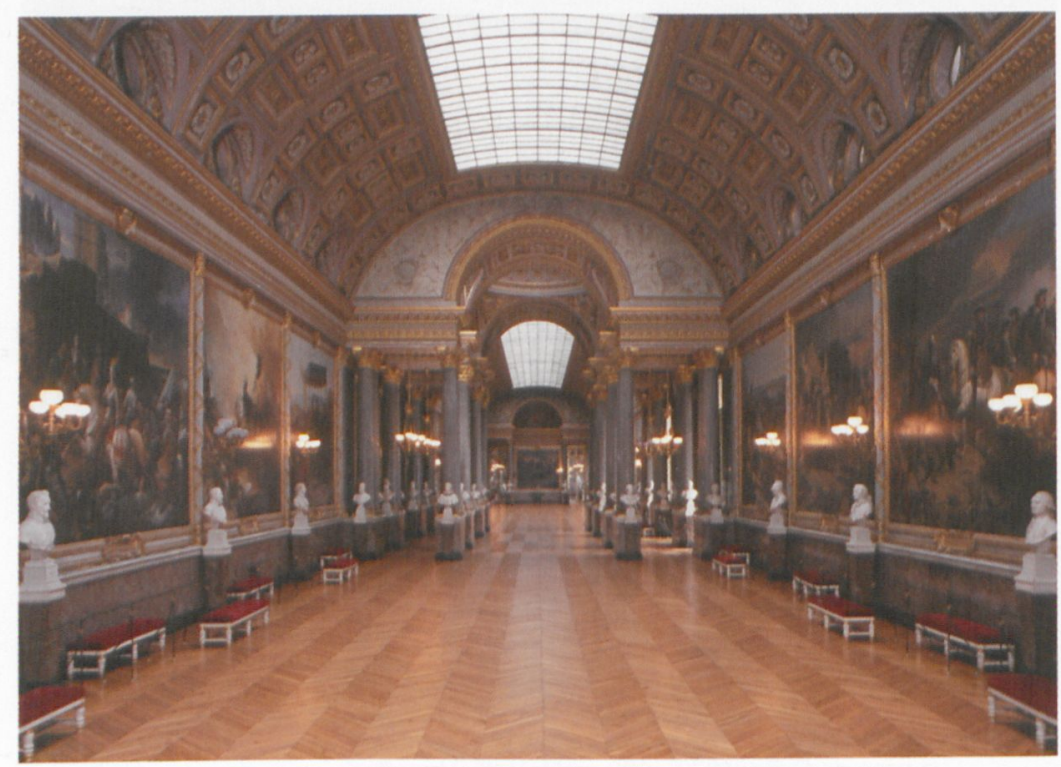

12. La galerie des Batailles du château de Versailles. 




13. La galerie des Glaces du palais royal (palais Durazzo) de Gênes. 


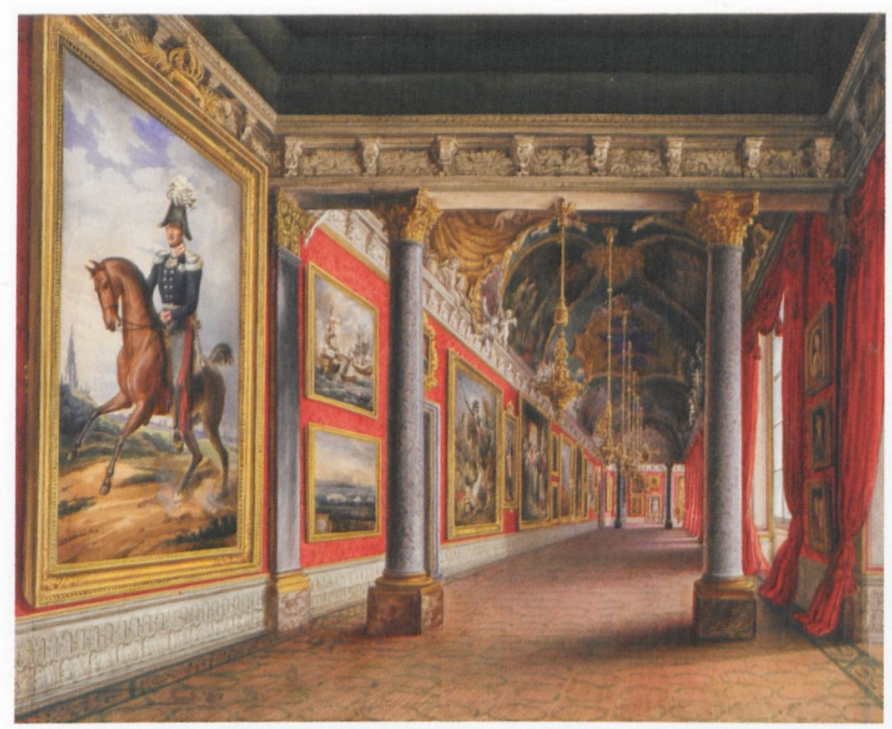

14. Carl Ludwig Rundt, vue de la Grande Galerie (alors Gemäldegalerie) vers l'ouest, 1852, Potsdam, Stiftung Preußische Schlösser und Gärten Berlin-Brandenburg.

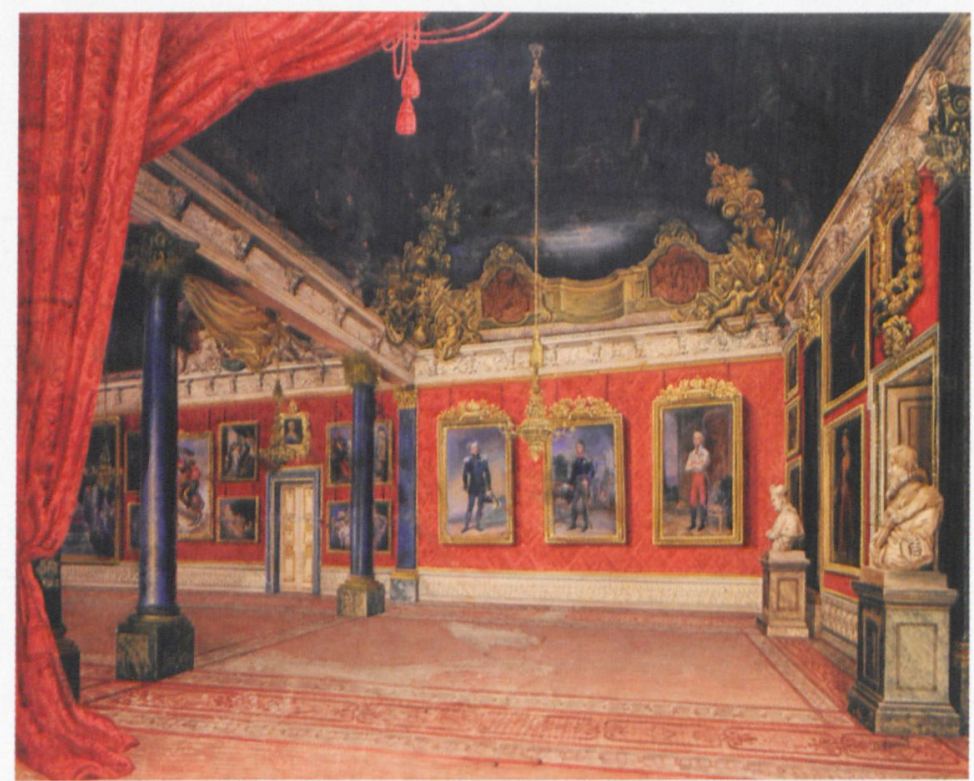

15. Carl Ludwig Rundt, pièce attenante occidentale, 1852 ,

Potsdam, Stiftung Preußische Schlösser und Gärten Berlin-Brandenburg. 


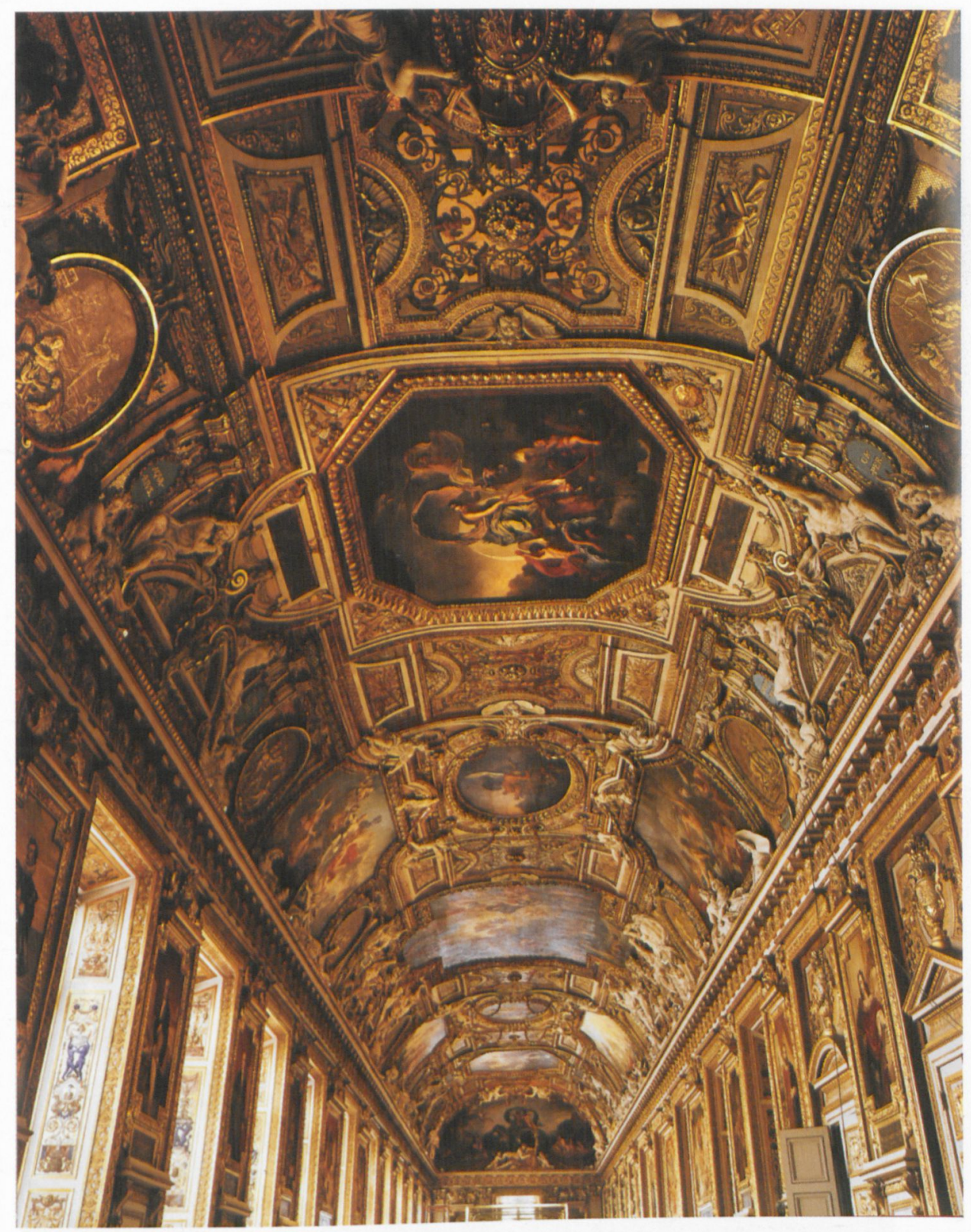

16. La galerie d'Apollon du musée du Louvre après sa restauration en 2004, Paris. 


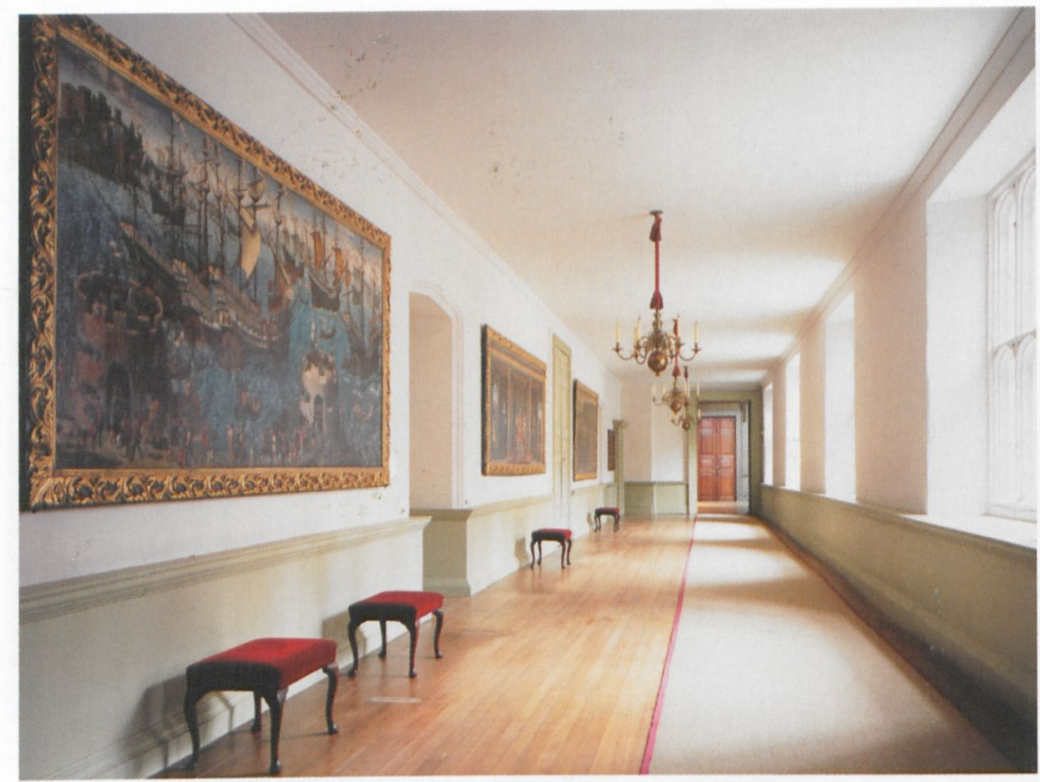

17. La Galerie hantée (Haunted Gallery) du palais de Hampton Court construite, vers 1528 , pour le cardinal Thomas Wolsey.

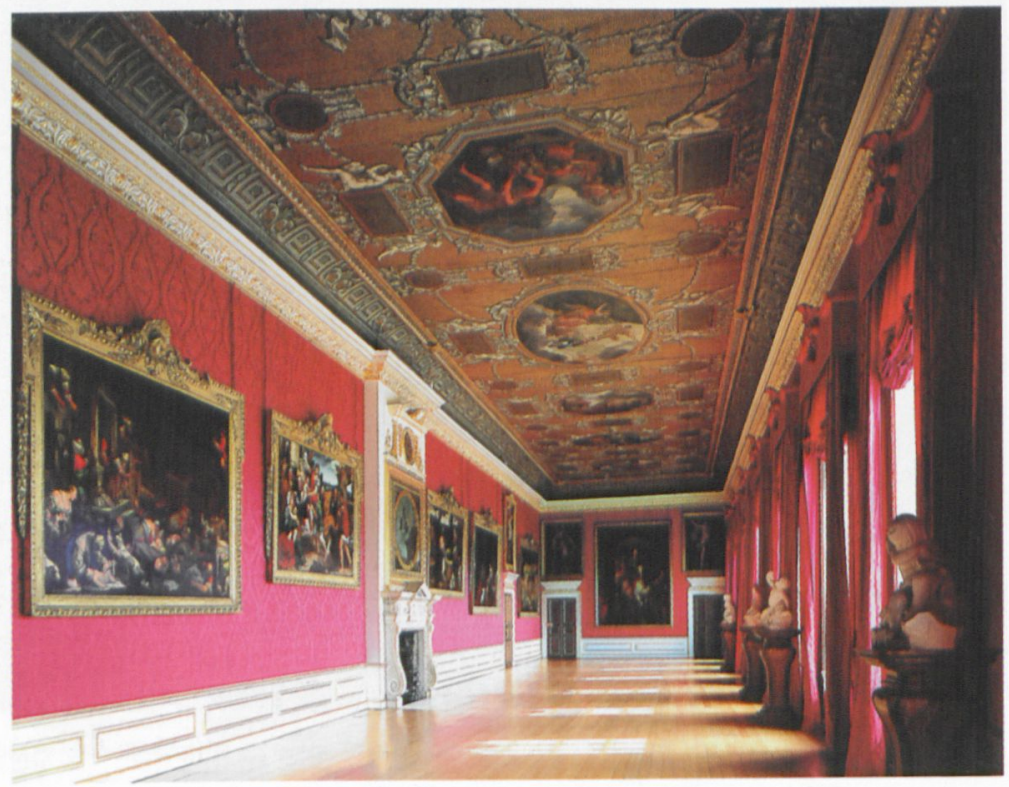

18. La Galerie du roi (King's Gallery) du palais de Kensington construite vers 16951697 pour Guillaume III et rénovée vers 1726 pour Georges Ier. 


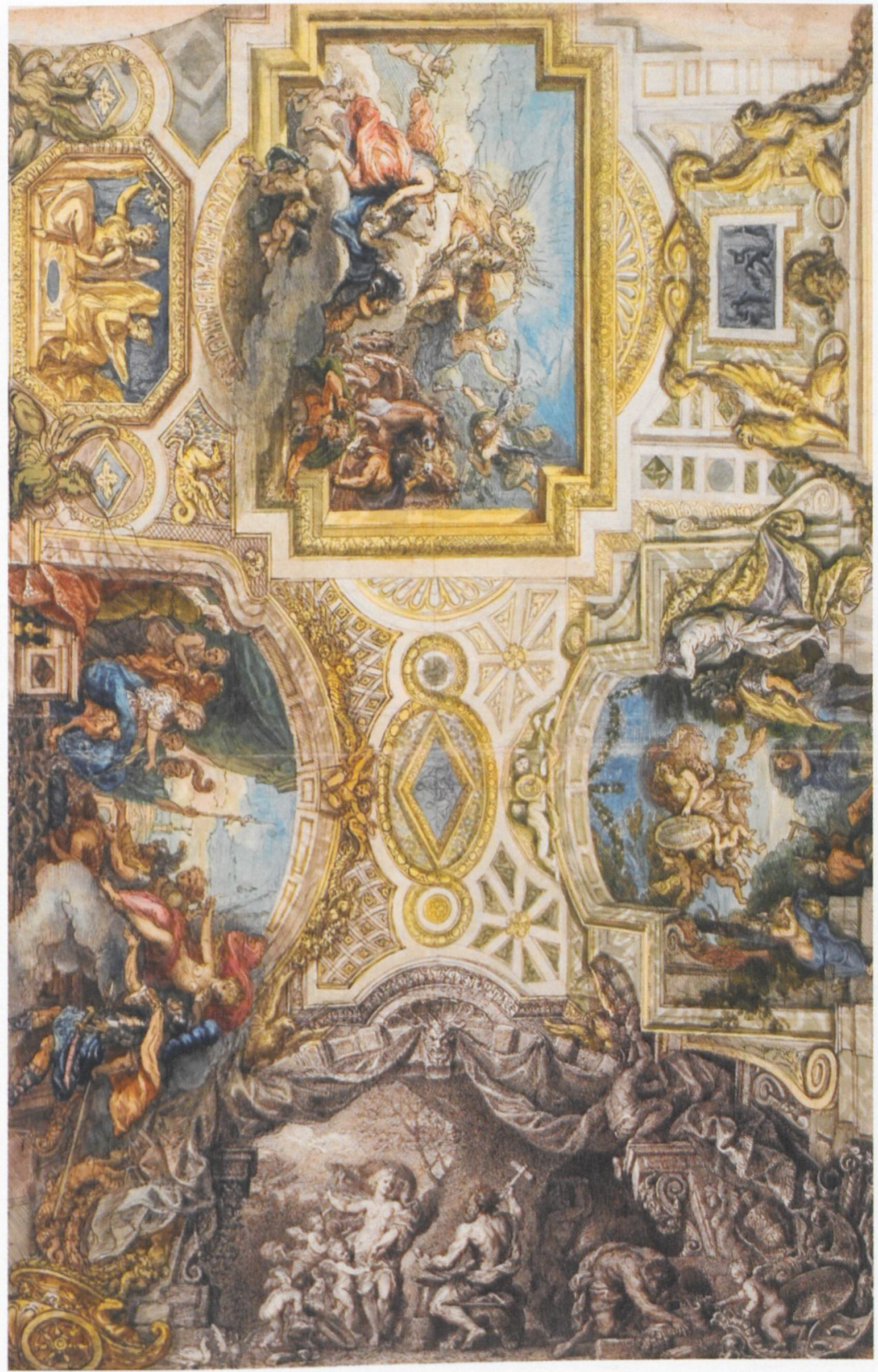

19. Artiste français (Michel Corneille l'Aîné ?), projet de décor pour un plafond de galerie figurant l'histoire d'Énée, Stockholm, Nationalmuseum. 


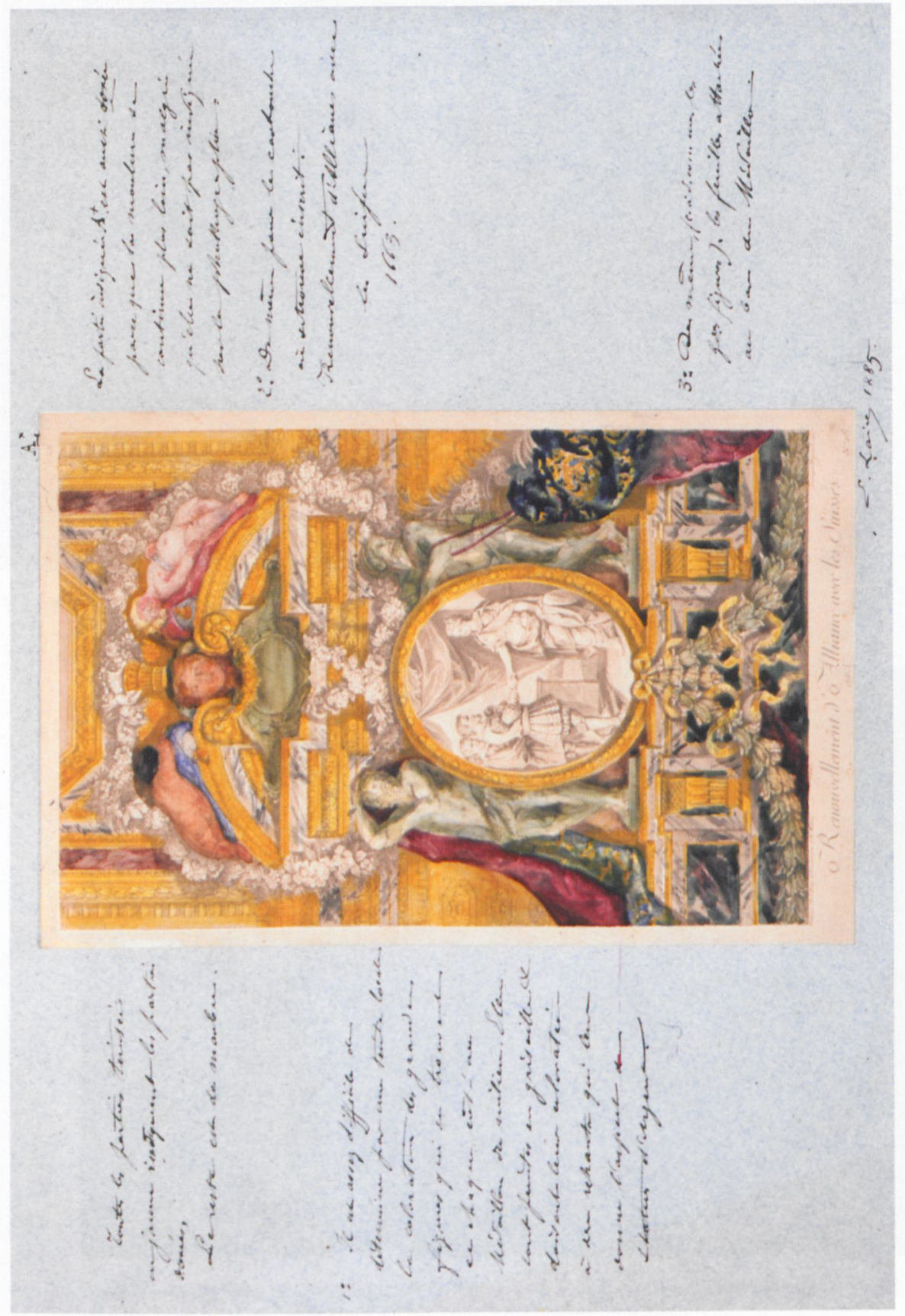

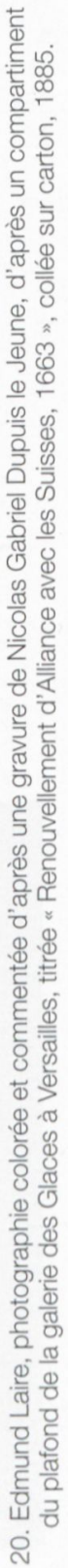


21. Vue vers le nord de la galerie des Glaces du nouveau château de Herrenchiemsee.
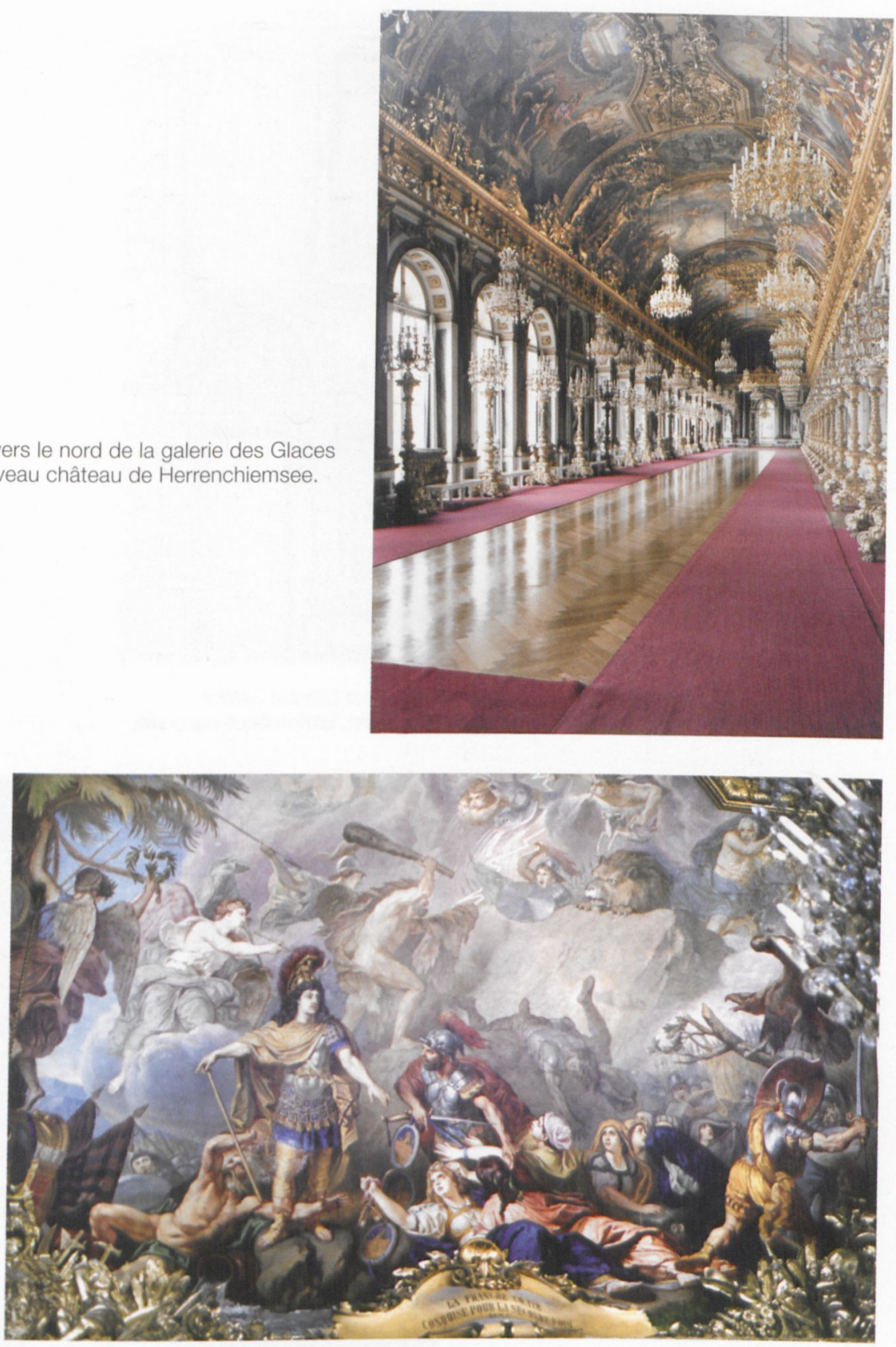

22. Eduard Schwoiser, La Franche-Comté conquise pour la seconde fois, 1674, 1880-1885, nouveau château de Herrenchiemsee, galerie des Glaces. 


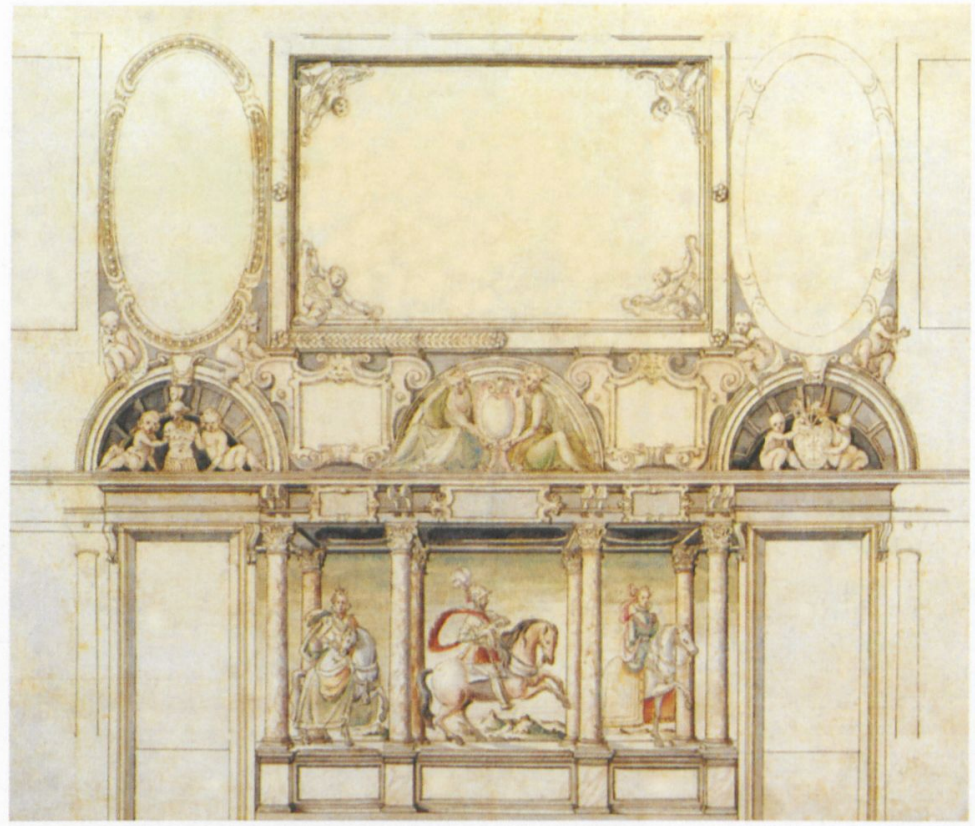

23. Carlo di Castellamonte, Premier projet pour la Grande Galerie de Charles Emmanuel ler, duc de Savoie, vers 1605, Turin, Bibliothèque nationale.

24. Artiste français au service des Bâtiments du roi (?), projet de décor de plafond, vers 1670 , Stockholm, Nationalmuseum.

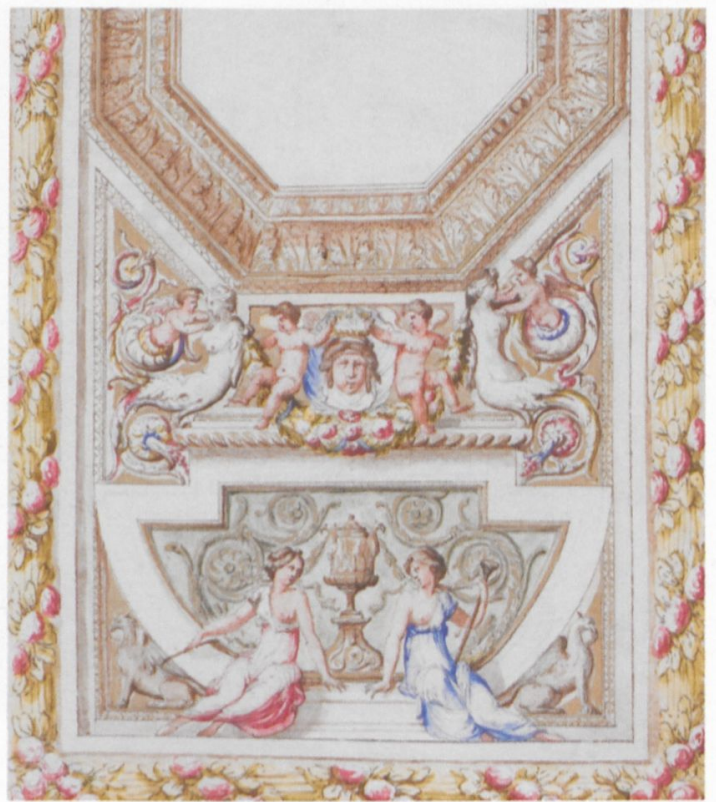

